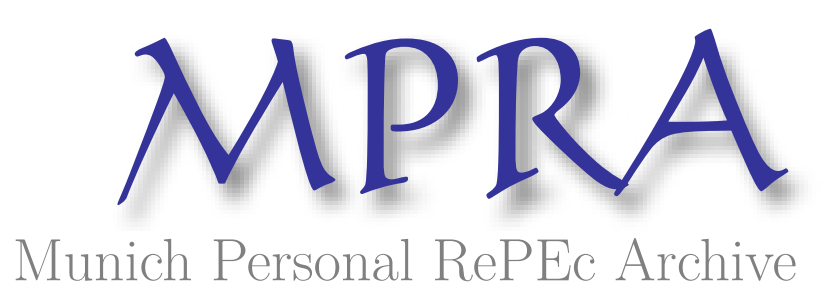

Structural change and the growth of industrial sectors: empirical test of a GPT model

Castellacci, Fulvio

2008

Online at https://mpra.ub.uni-muenchen.de/27592/

MPRA Paper No. 27592, posted 21 Dec 2010 13:25 UTC 


\title{
Structural Change and the Growth of Industrial Sectors: Empirical Test of a GPT Model
}

\author{
Fulvio Castellacci \\ Department of International Economics, \\ Norwegian Institute of International Affairs (NUPI), \\ POB 8159, Dep. 0033 Oslo, Norway \\ E-mail address: fc@nupi.no
}

NUPI Working Paper 745, Year 2008

\begin{abstract}
This paper investigates the empirical relevance of a model of structural change and the growth of industrial sectors. The model analyses the process of diffusion of general-purpose technologies (GPTs) and how this affects the dynamic performance of manufacturing and service industries. The empirical analysis studies the dynamics and the determinants of labour productivity growth for a large number of sectors in 18 OECD countries over the period 1970-2005. The results of dynamic panel data and cross-sectional analysis provide support for the empirical validity of the model. Industries that are close to the core of ICT-related GPTs are characterized by greater innovative capabilities and have recently experienced a more dynamic performance. Relatedly, countries that have been able to shift their industrial structure towards these high-opportunity manufacturing and service industries have grown more rapidly.
\end{abstract}

Keywords: structural change; productivity growth; GPT; innovation; service industries; EU KLEMS data; CIS data 


\section{Introduction}

Advanced countries have in recent decades undertaken a process of industrial transformation and structural change characterized by an increasing importance of the service sectors and a declining weight of manufacturing activities. Service industries have recently shown a remarkable dynamism, which has induced expectations about their possible role as the new engine of growth in the knowledge-based economy.

One major explanation for the increasing importance of services focuses on the technological dynamics of this branch of the economy. According to this view, the growth of services cannot simply be explained in terms of the outsourcing of manufacturing activities previously performed within manufacturing, or the changing consumption patterns induced by the dynamics of income and wealth. Services are becoming a key engine of growth, first and foremost, because of the high technological content and great knowledge intensity that characterize their production and provision (Evangelista, 2000; Drejer, 2004; Hartwig, 2008).

The focus on the creation and diffusion of advanced knowledge in the service sectors naturally calls the attention to the emergence and diffusion of the new set of generalpurpose technologies (GPTs) related to information and communication technologies (ICTs) in the last couple of decades (Bresnahan and Trajtenberg, 1995; Freeman and Louça, 2001; Lipsey, Carlaw and Bekar, 2005). The new ICT-based GPTs represent a set of radical and interrelated technological innovations that have the potential to lead to rapid productivity increases in many sectors of the economy. Many service industries, due to the intangible and knowledge-based nature of the activities they carry out, are closely related to the core of the new GPTs, since they are both active producers and users of ICTs (van Ark et al., 2008).

Further, the increasing adoption and use of ICT-related innovations create new opportunities for knowledge exchanges between service and manufacturing industries (e.g. software, hardware and telecommunications), so that vertical linkages between these interrelated branches of the economy are increasingly becoming a key factor of economic growth and competitiveness (Guerrieri and Meliciani, 2005).

This type of theoretical perspective - according to which structural change is related to the emergence and diffusion of ICT-related innovations - raises interesting questions that need to be confronted with empirical evidence. Three interrelated questions will be empirically examined in this paper: (1) Is it effectively the case that 
industries that are more closely related to the production and use of the new GPTs have recently improved their productivity performance? (2) To what extent is this productivity dynamics related to the technological capability and innovative activities of industrial sectors? (3) What are the country-level implications of this process of structural change - does the latter affect the growth rate of national economies?

These questions are certainly not new, and the study of the relationships between innovation, structural change and economic growth represents an increasingly important body of research (Peneder, 2003; Castaldi, 2008; Castellacci, 2008a). In order to critically re-examine these questions, we propose a new theoretical framework and test it by making use of new and updated data sources.

Our theoretical framework is based on a new model of GPT diffusion, structural change and productivity growth. The model identifies various groups of manufacturing and service industries, and points out their distinct technological characteristics and the different function they assume in the economic system as providers and/or recipients of advanced knowledge, goods and services to/from the other sectors. The model argues that, when a new set of GPTs emerge and diffuse throughout the economy, these sectoral groups greatly differ in their ability to exploit the emerging technological opportunities. ICT-related manufacturing and service industries are supposedly those that are in a better position to transform technological opportunities into productivity increases, and for this reason are expected to experience a more dynamic performance. ${ }^{1}$

We investigate these questions by making use of two fresh data sources. The first is the EU KLEMS database, a recent dataset that provides data on labour productivity and several other indicators of the economic characteristics of industrial sectors (2digit level) for all manufacturing and service industries for the period 1970-2005 (EU KLEMS Database, March 2008; Timmer et al., 2007; O’Mahony and Timmer, 2009). The second is the Fourth Community Innovation Survey (CIS4), which provides a rich set of information on innovative activities, strategies and linkages of industrial sectors in Europe in the more recent period 2002-2004. The econometric analysis

\footnotetext{
${ }^{1}$ As explained in further details in section 2 below, an important antecedent of our model is the formalization recently presented by Carlaw and Lipsey (2007), which puts forward a general framework where multiple GPTs complement and compete with each other. Our model differs from Carlaw and Lipsey's in terms of the description of the industrial structure of the economy and its focus on the derivation of testable predictions and hypotheses for the empirical analysis.
} 
examines these data by means of both cross-sectional methods and dynamic panel model techniques (Arellano and Bond, 1991).

The paper is organized as follows. Section 2 presents the GPT model and the three main hypotheses (each of which is related to the three research questions pointed out above). Sections 3, 4 and 5 analyse the empirical validity of these three propositions. Section 6 concludes and briefly discusses the implications of the results.

\section{GPT model and hypotheses}

Models in the GPT tradition focus on the importance of general purpose technologies (GPTs) for the growth process. Lipsey, Carlaw and Bekar (2005: 98) define a GPT as "a single generic technology, recognizable as such over its whole lifetime, that initially has much scope for improvement and eventually comes to be widely used, to have multiple uses, and to have many spillover effects". Thus, a key characteristic of a GPT is its pervasive nature, i.e. that it has the potential to lead to rapid productivity increases in many sectors of the economy for a prolonged period of time. In order to have such a pervasive and long-lasting effect, however, a GPT requires some changes in the set of socio-institutional characteristics that support and facilitate its development (so-called facilitating structure, see Lipsey, Carlaw and Bekar, 2005).

When a new GPT (or a set of interrelated GPTs) is well supported and matched by the corresponding facilitating structure, it may lead to periods characterized by prolonged and rapid growth that are sometimes referred to as revolutions. Typical examples are the so-called Fordist age during the post-war decades (characterized by the rise and diffusion of new GPTs based on radical innovations in petrochemical and automotive technologies), or, more recently, the ICT revolution driven by the GPT of programmable computing networks and related technologies (Carlaw, Lipsey and Webb, 2007).

Recent models in the GPT tradition formalize the emergence and diffusion of GPTs by modelling the transmission of new technologies from a GPT-producing sector to other downstream industries that implement and develop further the new products and processes (Bresnahan and Trajtenberg, 1995; Helpman and Trajtenberg, 1998; Carlaw and Lipsey, 2006). So far, the main interest of these modelling exercises has been to explain the slump (recession phase) that an economy may experience in the 
introduction and take-off phase of a new GPT, e.g. caused by a slow initial diffusion of the new set of radical technologies.

An important recent contribution is the model by Carlaw and Lipsey (2007), which puts forward a general theoretical framework where GPTs may occur in several different technology classes, in each of which there may be many different versions of a GPT competing with each other. In each technology class, as the productivity of a new GPT grows as a logistic function, it progressively attracts more resources and will eventually prevail over older GPTs.

Our model is rooted in this general modelling framework provided by Carlaw and Lipsey (2007). However, it differs from it in two main respects. First, we provide a different description of the industrial structure of the economy. We identify various groups of sectors in line with taxonomies and classification exercises previously presented in the innovation literature (Pavitt, 1984; Miozzo and Soete, 2001; O’Mahony and van Ark, 2003; Castellacci, 2008; Peneder, 2008). For each sectoral group, we point out its function as provider (recipient) of advanced knowledge, goods and services to (from) other branches of the economy. In particular, we highlight the importance of service activities, which play an increasingly vital role in the ICT-based age. Thus, an explicit endeavour of our model is to provide a bridge between the literature on sectoral patterns of innovation and the GPT modelling tradition. Secondly, we focus on the aggregate implications and testable predictions of the model, and analyse these empirically in the next sections of the paper. ${ }^{2}$

\subsection{The GPT model}

The main idea of the model is presented in the diagram in figure 1. The diagram points out four major macro-sectors (or industry groups), which differ in terms of their technological capability (X-axis) and the function they play in the economic system (i.e. their stage in the product chain; Y-axis). Advanced knowledge providers (AKP) produce advanced knowledge related to the new GPT. Two macro-sectors produce intermediate goods and services: one produces mass production goods (MPG), and the other provides supporting infrastructure services (SIS). Finally, the group of personal goods and services (PGS) produces items for the final consumption

\footnotetext{
${ }^{2}$ In order to derive testable predictions and hypotheses for the empirical analysis, our modelling framework is not as general as Carlaw and Lipsey's (2007) model. In particular, instead of allowing for the existence of multiple GPTs, we describe the process of competition between two GPTs only, an old and a new one.
} 
market. The overall idea is that, in order to diffuse throughout the economy and reach its full potential, a new GPT must be implemented and developed by all of these industry groups. In particular, a new GPT needs to be produced on a large scale, supported by an efficient infrastructure and sustained by an advanced knowledge base. The arrows in figure 1 represent the transmission mechanism of the GPT, i.e. the exchange of knowledge, goods and services among the various sectoral groups.

\section{$<$ Figure 1 here $>$}

\section{Advanced knowledge providers (AKP)}

This type of industries is characterized by great technological capability and a significant ability to create and manage complex technological knowledge. Two distinct groups are typically distinguished in the innovation literature (Pavitt, 1984; Miozzo and Soete, 2001; Castellacci, 2008):

(1) AKP-M: within the manufacturing branch, specialized suppliers of machinery, equipment and precision instruments;

(2) AKP-S: within the service branch, providers of specialized knowledge and technical solutions like software, R\&D, engineering and consultancy (so-called knowledge-intensive business services).

What these industries have in common is that, in addition to their high level of technological capability, they perform the same function in the economic system as providers of advanced technological knowledge to other industrial sectors. They represent the supporting knowledge base upon which innovative activities in all other sectors are built, and they continuously upgrade and renew this base. Firms in these industries are typically small, and tend to develop their technological activities in close cooperation with their clients and with the users of the new products and services they create. In the post-war era, the typical example of this kind of userproducer interactions was Pavitt's (1984) illustration of the close ties between specialized suppliers and car producers in the automotive industry. In more recent times, the greater technological specialization and deeper division of labour have increased the demand for complex innovative capabilities, leading to the emergence 
and rapid growth of knowledge-intensive business services, which now act as providers of specialized knowledge and technical solutions for the other advanced branches of the economic system.

Advanced knowledge providers produce output $\mathrm{Y}_{\mathrm{AKP}}$ by employing a given quantity of skilled labour $\mathrm{L}_{\mathrm{AKP}}{ }^{3}$ :

$\mathrm{Y}_{\mathrm{AKP}}=\mathrm{A}_{\mathrm{AKP}} \cdot \mathrm{f}\left(\mathrm{L}_{\mathrm{AKP}}\right)$

We assume that the productivity of the two sub-groups of advanced knowledge providers ( $\mathrm{A}_{\mathrm{AKP}-\mathrm{M}}$ and $\left.\mathrm{A}_{\mathrm{AKP}-\mathrm{S}}\right)$ evolve over time as a logistic function:

$A_{A K P-M}(t)=\operatorname{Max} A_{A K P-M} /\left[1+\exp \left(t_{1}-\beta_{\text {AKP-M }} \cdot t\right)\right]$

$\mathrm{A}_{\mathrm{AKP}-\mathrm{S}}(\mathrm{t})=\operatorname{Max} \mathrm{A}_{\mathrm{AKP}-\mathrm{S}} /\left[1+\exp \left(\mathrm{t}_{1}-\beta_{\mathrm{AKP}-\mathrm{S}} \cdot \mathrm{t}\right)\right]$

The logistic function is frequently used to model the process of diffusion of a new GPT (Carlaw and Lipsey, 2007). A logistic productivity function represents the idea that the productivity of a new GPT has initially a low growth phase, due to the initial slow diffusion of the new technological paradigm. It then takes off at time $t_{1}$, follows a rapid speed of diffusion ( $\beta_{\mathrm{AKP}-\mathrm{M}}$ and $\beta_{\mathrm{AKP}-\mathrm{S}}$ ), and finally slows down again and settles around its maximum value (Max $\mathrm{A}_{\mathrm{AKP}-\mathrm{M}}$ and Max $\mathrm{A}_{\mathrm{AKP}-\mathrm{S}}$ ) at the end of the long-run GPT cycle.

The parameters measuring the slope of the logistic function $\left(\beta_{\mathrm{AKP}-\mathrm{M}} \neq \beta_{\mathrm{AKP}-\mathrm{S}}\right)$ represent in our model the technological capability of each sectoral group. The idea is that the higher the technological capability of a sector the more rapid will be the growth of productivity during the diffusion phase of the new GPT. On the other hand, the parameters measuring the ceiling of the logistic (Max $A_{A K P-M} \neq \operatorname{Max} A_{A K P-S}$ ) represent the maximum productivity that each sectoral group may achieve after the full implementation of a new GPT.

The aggregate productivity of the advanced knowledge providers macro-sector $\left(\mathrm{A}_{\mathrm{AKP}}\right)$ is given by the (weighted) average of the productivity in the two sub-sectors:

\footnotetext{
${ }^{3}$ For simplicity, we assume that they do not use any physical capital. This assumption could easily be removed without affecting the main properties and outcomes of the model.
} 
$A_{A K P}(t)=A_{A K P-M}\left(Y_{A K P-M} / Y_{A K P}\right)+A_{A K P-S}\left(Y_{A K P-S} / Y_{A K P}\right)$

Hence, given the properties of the logistic equations (2) and (3) above, the dynamics of $A_{\mathrm{AKP}}$ is positively related to the four parameters $\beta_{\mathrm{AKP}-\mathrm{M}}, \beta_{\mathrm{AKP}-\mathrm{S}}$, Max $\mathrm{A}_{\mathrm{AKP}-\mathrm{M}}$ and Max A AKP-S.

\section{Mass production goods (MPG)}

These constitute a key part of the manufacturing branch. They may be located at an intermediate stage of the vertical chain, since they mostly produce intermediate products used in other stages of the production process. In terms of their technological capability, they are characterized by a considerable capacity to develop new products and processes internally, although two distinct sub-groups may be distinguished (Pavitt, 1984):

(1) MPG-SB: science-based sectors (such as electronics) are characterized by a great ability to create new technological knowledge internally, and their innovation processes are closely related to the scientific advances continuously achieved by universities and other public research institutes;

(2) MPG-SI: scale-intensive industries (e.g. motor vehicles and other transport equipment) typically have their own in-house $R \& D$ facilities, and their innovative activities also develop in close cooperation with the specialized suppliers of precision instruments and machinery described above.

Different as they may be, these sectoral groups share several common characteristics. Firms are typically large, and their profitability depends on the exploitation of scale economies that can be obtained through the mass production of standardized goods. Further, they all assume a central position in the knowledge chain, as they receive technological inputs from advanced knowledge providers, while in turn providing technological outputs (new products and intermediate goods) that are used by infrastructure services as well as by the producers of final goods. They are, in a nutshell, the carrier industries of a new technological paradigm (Freeman and Louça, 2001). By producing technologically advanced products on a large scale, by fostering the efficiency and quality of the production process of infrastructure and final goods 
and services, and by increasing the demand for specialized solutions from advanced knowledge providers, this group of industrial sectors plays a pivotal role in the economic system.

They produce output $\mathrm{Y}_{\mathrm{MPG}}$ by employing labour $\mathrm{L}_{\mathrm{MPG}}$ and capital $\mathrm{K}_{\mathrm{MPG}}$ :

$\mathrm{Y}_{\mathrm{MPG}}=\mathrm{A}_{\mathrm{MPG}} \cdot \mathrm{f}\left(\mathrm{L}_{\mathrm{MPG}} ; \mathrm{K}_{\mathrm{MPG}}\right)$

The capital they use in the production process has two distinct components: one is the advanced knowledge and specialised instruments acquired from the AKP macrosector, whereas the other is the set of infrastructure services that they purchase from the SIS macro-sector (the latter is described in further details below). In other words, the output of these two macro-sectors $\left(\mathrm{Y}_{\mathrm{AKP}}\right.$ and $\left.\mathrm{Y}_{\mathrm{SIS}}\right)$ is acquired from the massproduction goods producers, thus representing advanced knowledge embodied in the physical capital they employ:

$\mathrm{K}_{\mathrm{MPG}}=\theta_{\mathrm{MPG}} \cdot \mathrm{g}\left(\mathrm{Y}_{\mathrm{AKP}} ; \mathrm{Y}_{\mathrm{SIS}}\right)$

This process of embodied knowledge acquisition is proportional to the parameter $\theta_{\mathrm{MPG}}\left(0<\theta_{\mathrm{MPG}}<1\right)$, which represents the ability of the sector to acquire external knowledge from their suppliers and other upstream industries.

The productivity of the two sub-groups of industries within this macro-sector ( $\mathrm{A}_{\mathrm{MPG}-\mathrm{SI}}$ and $\mathrm{A}_{\mathrm{MPG}-\mathrm{SB}}$ ) evolves again as a logistic function:

$\mathrm{A}_{\mathrm{MPG}-\mathrm{SI}}(\mathrm{t})=\operatorname{Max} \mathrm{A}_{\mathrm{MPG}-\mathrm{SI}} /\left[1+\exp \left(\mathrm{t}_{0}-\beta_{\mathrm{MPG}-\mathrm{SI}} \bullet \mathrm{t}\right)\right]$

$\mathrm{A}_{\mathrm{MPG}-\mathrm{SB}}(\mathrm{t})=\operatorname{Max} \mathrm{A}_{\mathrm{MPG}-\mathrm{SB}} /\left[1+\exp \left(\mathrm{t}_{1}-\beta_{\mathrm{MPG}-\mathrm{SB}} \cdot \mathrm{t}\right)\right]$

However, differently from equations (2) and (3) presented above, the two logistic functions are here assumed to differ from each other in one important respect. In line with the innovation literature (e.g. Pavitt, 1984; Castellacci, 2008), we assume that scale-intensive sectors (MPG-SI) make a greater use of the old GPT, whereas sciencebased industries (MPG-SB) are more closely related to the new GPT. For simplicity of exposition, we will therefore refer to them as the old GPT group (MPG-SI) and the new GPT group (MPG-SB) respectively. To be clear, both sectoral groups may use a 
new GPT (e.g. programmable computing networks, see Carlaw, Lipsey and Webb, 2007), but the MPG-SB group is assumed to be a more active producer and user of the new GPT than the MPG-SI group. ${ }^{4}$

Therefore, the functional form of the logistic in the two equations (7) and (8) is the same, but the parameters describing the dynamics of productivity of the two subgroups are different: $(i) \mathrm{t}_{1}>\mathrm{t}_{0}$ (the take-off phase of the new GPT obviously arrives later than the one of the old GPT); (ii) $\beta_{\text {MPG-SB }}>\beta_{\text {MPG-SI }}$ (the technological capability in the new GPT group is greater than in the old GPT group); (iii) Max $\mathrm{A}_{\mathrm{MPG}-\mathrm{SB}}>\mathrm{Max}$ $\mathrm{A}_{\text {MPG-SI }}$ (the full potential of the new GPT is higher than the one that it was possible to achieve by using the old GPT).

The interesting point about this formalization is that, in line with Carlaw and Lipsey's (2007) model, we allow for the simultaneous existence of two GPTs (old and new). The process of competition between the old and the new GPT is represented by the following two equations:

$\mathrm{L}_{\mathrm{MPG}-\mathrm{SB}}(\mathrm{t})-\mathrm{L}_{\mathrm{MPG}-\mathrm{SB}}(\mathrm{t}-1)=\alpha_{\mathrm{MPG}}\left[\mathrm{A}_{\mathrm{MPG}-\mathrm{SB}}(\mathrm{t})-\mathrm{A}_{\mathrm{MPG}-\mathrm{SB}}(\mathrm{t}-1)\right]$

$\mathrm{L}_{M P G-S I}(\mathrm{t})=\mathrm{L}_{\mathrm{MPG}}(\mathrm{t})-\mathrm{L}_{\mathrm{MPG}-\mathrm{SB}}(\mathrm{t})$

Equation (9) points out that the amount of labour resources employed in the new GPT sector (L $\left.\mathrm{L}_{\mathrm{MPG}-\mathrm{SB}}\right)$ grows over time as a function of the dynamics of its productivity. If the productivity of the new GPT-related sector is rising (say, after the take-off point of the logistic), workers are more likely to move from the old to the new GPT sectors. This reallocation process is gradual, and it proceeds proportionally to the parameter $\alpha_{\mathrm{MPG}}\left(0<\alpha_{\mathrm{MPG}}<1\right)$, which represents the facility for structural change. Equation (10) is instead a full-employment condition, imposing for simplicity that all workers that are not employed in the new GPT sector are employed in the old one.

Finally, we define the aggregate productivity of the macro-sector $\left(A_{M P G}\right)$ as the (weighted) average of the productivities in the old and new GPT sectors:

$\mathrm{A}_{\mathrm{MPG}}(\mathrm{t})=\mathrm{A}_{\mathrm{MPG}-\mathrm{SI}}\left(\mathrm{Y}_{\mathrm{MPG}-\mathrm{SI}} / \mathrm{Y}_{\mathrm{MPG}}\right)+\mathrm{A}_{\mathrm{MPG}-\mathrm{SB}}\left(\mathrm{Y}_{\mathrm{MPG}-\mathrm{SB}} / \mathrm{Y}_{\mathrm{MPG}}\right)$

\footnotetext{
${ }^{4}$ This assumption is based on the literature on sectoral patterns of innovation, and is corroborated by the empirical findings that will be described in section 4 below.
} 
Given the equations (5) to (11), the dynamics of $\mathrm{A}_{\mathrm{MPG}}$ is positively related to the following parameters: $(i) \alpha_{\mathrm{MPG}}$, the facility for structural change in the MPG macro-

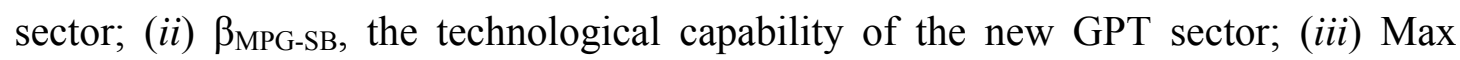
$\mathrm{A}_{\mathrm{MPG}-\mathrm{SB}}$, the maximum productivity that it is possible to achieve by implementing the new GPT; (iv) $\theta_{\mathrm{MPG}}$, the ability of the macro-sector MPG to acquire external knowledge.

\section{Supporting infrastructure services (SIS)}

This macro-sector may be located, similarly to the previous one, at an early stage of the vertical chain, since it mostly produces intermediate services rather than items for personal consumption. It differs from the group of mass production goods producers (MPG) in two main respects: first, these industries provide infrastructure services instead of intermediate capital goods; secondly, they are typically characterized by a lower technological capability, particularly with respect to their more limited ability to develop new knowledge internally. Their innovative trajectory tends in fact to be based on the acquisition of machinery, equipment and various types of advanced technological knowledge created elsewhere in the economic system. Two sub-groups of sectors are usually distinguished in the innovation literature (Miozzo and Soete, 2001):

(1) SIS-N: providers of network infrastructure services (such as finance and telecommunications);

(2) SIS-P: providers of physical and distributive infrastructure services (e.g. transport and wholesale trade).

Firms in the former group typically make active use of ICTs in order to increase the efficiency of the productive process and the quality of their services, whereas the latter group of industries has significantly less capability in this respect. Regardless of these differences, what these sectoral groups have in common is the function they assume in the economic system: they represent the supporting infrastructure upon which business and innovative activities carried out by firms in the whole economy are based. The more advanced this infrastructure is, the easier the process of inter- 
sectoral knowledge diffusion within the domestic economy, and the more efficient and productive the national system will be.

Supporting infrastructure service (SIS) industries produce output $\mathrm{Y}_{\mathrm{SIS}}$ by employing labour $\mathrm{L}_{\mathrm{SIS}}$ and capital $\mathrm{K}_{\mathrm{SIS}}$ :

$\mathrm{Y}_{\mathrm{SIS}}=\mathrm{A}_{\mathrm{SIS}} \cdot \mathrm{f}\left(\mathrm{L}_{\mathrm{SIS}} ; \mathrm{K}_{\mathrm{SIS}}\right)$

The capital they use in the production process is purchased from the advanced knowledge providers $\left(\mathrm{Y}_{\mathrm{AKP}}\right)$ and the mass production goods $\left(\mathrm{Y}_{\mathrm{MPG}}\right)$ macro-sectors:

$\mathrm{K}_{\mathrm{SIS}}=\theta_{\mathrm{SIS}} \cdot \mathrm{g}\left(\mathrm{Y}_{\mathrm{AKP}} ; \mathrm{Y}_{\mathrm{MPG}}\right)$

Again, we assume this process of embodied knowledge acquisition to proceed proportionally to the parameter $\theta_{\mathrm{SIS}}\left(0<\theta_{\mathrm{SIS}}<1\right)$, so that the greater the latter the faster and more intense the process of acquisition of advanced knowledge, machineries and precision instruments produced by other upstream sectors.

The dynamics of productivity of this macro-sector is analogous to the one described above for the mass production goods producers (MPG). We allow for the existence of two GPTs, old and new, and assume that physical infrastructure services (SIS-P) are more active producers and users of the old GPT, whereas network infrastructure services are more closely related to the new GPT (e.g. PCN or other ICT-related technologies). As specified above, for simplicity of exposition we will refer to them as the old GPT group (SIS-P) and the new GPT group (SIS-N) respectively. The dynamics of productivity of these two sub-sectors follows again a logistic function:

$\operatorname{A}_{\text {SIS-P }}(t)=\operatorname{Max} A_{\text {SIS-P }} /\left[1+\exp \left(t_{0}-\beta_{\text {SIS-P }} \bullet t\right)\right]$

$A_{\text {SIS-N }}(t)=\operatorname{Max} A_{\text {SIS-N }} /\left[1+\exp \left(t_{1}-\beta_{\text {SIS-N }} \bullet t\right)\right]$

Similarly to what previously assumed, these two logistic equations differ in terms of the following parameters: $(i) \mathrm{t}_{1}>\mathrm{t}_{0}$ (the take-off phase of the new GPT arrives later than the old GPT); (ii) $\beta_{\text {SIS-N }}>\beta_{\text {SIS-P }}$ (the technological capability in the new GPT group is greater than in the old); (iii) Max $A_{\text {SIS-N }}>$ Max $A_{\text {SIS-P }}$ (the full potential of the new GPT is higher than the one achieved by the old GPT). 
The process of competition between the two GPTs and the gradual reallocation of labour resources from the old to the new GPT sectoral groups is also analogous to what previously described (see equations (9) and (10) above):

$\mathrm{L}_{\text {SIS-N }}(\mathrm{t})-\mathrm{L}_{\text {SIS-N }}(\mathrm{t}-1)=\alpha_{\text {SIS }}\left[\mathrm{A}_{\text {SIS-N }}(\mathrm{t})-\mathrm{A}_{\text {SIS-N }}(\mathrm{t}-1)\right]$

$\mathrm{L}_{\text {SIS-P }}(\mathrm{t})=\mathrm{L}_{\text {SIS }}(\mathrm{t})-\mathrm{L}_{\text {SIS-N }}(\mathrm{t})$

Equation (16) models the process of structural change from the old to the new GPT as a linear function of the parameter $\alpha_{\text {SIS }}$ (facility for structural change), and equation (17) assumes full employment in the macro-sector.

The aggregate productivity of this macro-sector is defined as the (weighted) average of the productivities in the old and new GPT sub-sectors ( $\mathrm{A}_{\text {SIS-P }}$ and $\left.\mathrm{A}_{\text {SIS-N }}\right)$ :

$A_{\text {SIS }}(t)=A_{\text {SIS-P }}\left(Y_{\text {SIS-P }} / Y_{\text {SIS }}\right)+A_{\text {SIS-N }}\left(Y_{\text {SIS-N }} / Y_{\text {SIS }}\right)$

Again, the dynamics of $A_{S I S}$ is positively related to these factors: $(i) \alpha_{S I S}$, the facility for structural change in the SIS macro-sector; (ii) $\beta_{\text {SIS-N, }}$, the technological capability of the new GPT sector; (iii) Max $\mathrm{A}_{\mathrm{SIS}-\mathrm{N}}$, the maximum productivity that it is possible to achieve by using the new GPT; (iv) $\theta_{\text {SIS }}$, the ability of the macro-sector SIS to acquire external knowledge.

\section{Personal goods and services (PGS)}

Located at the final stage of the vertical chain, these manufacturing and service industries are characterized by a lower technological content and a more limited ability to develop new products and processes internally. Their dominant innovation strategy is typically based on the acquisition of machinery, equipment and other types of external knowledge produced by their suppliers, while they commonly lack the capability and resources to organize and maintain their own R\&D labs. This explains the term supplier-dominated industries that is frequently adopted in the innovation literature - and that describes well the two sub-groups of industries included in this category:

(1) PGS-M: the producers of personal goods within manufacturing (Pavitt, 1984); 
(2) PGS-S: the providers of personal services within the service branch (Miozzo and Soete, 2001).

Firms in these manufacturing and service sectors, typically small enterprises, are mostly recipients of advanced knowledge. To the extent that they are able to implement new technologies created elsewhere in the economy, they may use them to improve the quality of the final goods and services they commercialise.

They produce final goods and services $\mathrm{Y}_{\mathrm{PGS}}$ by employing labour $\mathrm{L}_{\mathrm{PGS}}$ and physical capital K $\mathrm{PGS}_{\text {: }}$

$\mathrm{Y}_{\mathrm{PGS}}=\mathrm{A}_{\mathrm{PGS}} \cdot \mathrm{f}\left(\mathrm{L}_{\mathrm{PGS}} ; \mathrm{K}_{\mathrm{PGS}}\right)$

The latter is constituted by intermediate goods and services purchased from the SIS and MPG macro-sectors:

$\mathrm{K}_{\mathrm{PGS}}=\theta_{\mathrm{PGS}} \cdot \mathrm{g}\left(\mathrm{Y}_{\mathrm{SIS}} ; \mathrm{Y}_{\mathrm{MPG}}\right)$

Again, the parameter $\theta_{\mathrm{PGS}}\left(0<\theta_{\mathrm{PGS}}<1\right)$ measures the intensity of capital and embodied knowledge acquisition from upstream sectors.

Differently from the previous macro-sectors, we assume here for simplicity that the productivity of the personal goods and service producers (PGS) is fixed. In other words, the diffusion of a new GPT will not have any direct effect on the productivity of this traditional macro-sector, but will enhance the quality of the final consumption goods they produce by increasing the knowledge embodied in the physical capital component $\mathrm{K}_{\mathrm{PGS}}$. Therefore, the aggregate productivity of this macro-sector is given by the average of the productivities in the two sub-sectors ( $\mathrm{A}_{\mathrm{PGS}-\mathrm{M}}$ and $\mathrm{A}_{\mathrm{PGS}-\mathrm{S}}$ ):

$\mathrm{A}_{\mathrm{PGS}}=\mathrm{A}_{\mathrm{PGS}-\mathrm{M}}\left(\mathrm{Y}_{\mathrm{PGS}-\mathrm{M}} / \mathrm{Y}_{\mathrm{PGS}}\right)+\mathrm{A}_{\mathrm{PGS}-\mathrm{S}}\left(\mathrm{Y}_{\mathrm{PGS}-\mathrm{S}} / \mathrm{Y}_{\mathrm{PGS}}\right)$

\section{Country-level dynamics}

Let us now derive the country-level implications of the model, in order to point out the factors that determine cross-country differences in the long-run performance of 
national economies. The total output produced by each country $i\left(\mathrm{Y}_{i}\right)$ is defined as the sum of the output produced by the four macro-sectors described above:

$\mathrm{Y}_{i}=\mathrm{Y}_{\mathrm{PGS}}+\mathrm{Y}_{\mathrm{MPG}}+\mathrm{Y}_{\mathrm{SIS}}+\mathrm{Y}_{\mathrm{AKP}}$

The aggregate productivity of country $i\left(\mathrm{~A}_{i}\right)$ is defined as the (weighted) average of the productivities of the four macro-sectors:

$\mathrm{A}_{i}=\mathrm{A}_{\mathrm{PGS}}\left(\mathrm{Y}_{\mathrm{PGS}} / \mathrm{Y}_{i}\right)+\mathrm{A}_{\mathrm{MPG}}\left(\mathrm{Y}_{\mathrm{MPG}} / \mathrm{Y}_{i}\right)+\mathrm{A}_{\mathrm{SIS}}\left(\mathrm{Y}_{\mathrm{SIS}} / \mathrm{Y}_{i}\right)+\mathrm{A}_{\mathrm{AKP}}\left(\mathrm{Y}_{\mathrm{AKP}} / \mathrm{Y}_{i}\right)$

Hence, given the properties of the four sectoral productivity terms that have been analysed above ( $\mathrm{A}_{\mathrm{PGS}}, \mathrm{A}_{\mathrm{MPG}}, \mathrm{A}_{\mathrm{SIS}}, \mathrm{A}_{\mathrm{AKP}}$ ), we can conclude that the dynamics of productivity of country $i\left(\mathrm{~A}_{i}\right)$ is positively related to the following four main factors:

(i) the vector $\boldsymbol{\alpha}_{i}=\left[\alpha_{\mathrm{MPG}} ; \alpha_{\mathrm{SIS}}\right]$, whose components are the facility for structural change parameters in the MPG and SIS macro-sectors respectively, which determines the rapidity with which a country is able to shift labour resources from the old to the new GPT sectors;

(ii) the vector $\boldsymbol{\beta}_{i}=\left[\beta_{\mathrm{AKP}-\mathrm{M}} ; \beta_{\mathrm{AKP}-\mathrm{S}} ; \beta_{\mathrm{MPG}-\mathrm{SB}} ; \beta_{\mathrm{SIS}-\mathrm{N}}\right]$, whose components are the technological capabilities of the new GPT-related sectors;

(iii) the vector $\boldsymbol{\theta}_{\boldsymbol{i}}=\left[\theta_{\mathrm{MPG}} ; \theta_{\mathrm{SIS}} ; \theta_{\mathrm{PGS}}\right]$, whose components represent the ability of each macro-sector to acquire external knowledge from other upstream industries. ${ }^{5}$

(iv) the vector Max $\mathbf{A}_{i}=\left[\right.$ Max $\mathrm{A}_{\mathrm{AKP}-\mathrm{M}}$; Max $\mathrm{A}_{\mathrm{AKP}-\mathrm{S}}$; Max $\mathrm{A}_{\mathrm{MPG}-\mathrm{SB}}$; Max $\left.\mathrm{A}_{\mathrm{SIS}-\mathrm{N}}\right]$, which represents the maximum productivity that can be achieved in the new GPTrelated sectors by implementing the new GPT. ${ }^{6}$

\footnotetext{
${ }^{5}$ Note that this vector does not include the component $\theta_{\mathrm{AKP}}$, as our model assumes that advanced knowledge providers (AKP) do not acquire any embodied knowledge from the other sectors but do only employ skilled labour in their production process.

${ }^{6}$ As pointed out by a referee of this Journal, this set of parameters may also be considered to vary across countries because, although the GPT is the same, cross-country differences in terms of social, institutional and cultural factors may substantially affect its process of evolution, and hence determine the maximum productivity level that this may eventually achieve in different countries.
} 


\subsection{Testable predictions and hypotheses}

Let us finally point out more explicitly the main testable predictions and hypotheses that the model leads to formulate, and that will be empirically analysed in the next sections. The overall idea of the model is that when a new GPT emerges and diffuses throughout the economy, industrial sectors differ greatly in terms of the technological opportunities, capabilities and constraints they face (Bresnahan and Trajtenberg, 1995). High-opportunity branches are in a better position to exploit the advantages of the new GPT, and have a greater growth potential. Take for instance some of the industries belonging to our mass-production goods (MPG) macro-sector. By demanding new infrastructural services as well as advanced specialized knowledge and technical solutions to their suppliers, they transmit part of this growth potential to some of the other industrial groups.

To illustrate, the post-war period (so-called Fordist age, see Freeman and Louça, 2001) was characterized by the rise and diffusion of a new set of GPTs in petrochemical and automotive technologies (e.g. the diffusion and subsequent refinement of the cracking and of the internal combustion engine). In that period, the typical high-opportunity mass-production sectors included the chemical, plastics and automobile industries (Freeman et al., 1982). In order to follow their dynamic trajectories, these branches fostered the growth of specialized suppliers (e.g. producers of precision instruments) and of infrastructural services (e.g. physical infrastructural services like transport). It was the set of mutual interactions between these vertically integrated branches of the economy that sustained the dynamics of national systems in many advanced countries in the post-war era.

More recently, the economy has seen the surge of a new paradigmatic phase that is sometimes referred to as the ICT revolution, and which is based on a set of GPTs related to ICTs and the related ongoing transformations in the corresponding facilitating structure (Lipsey, Carlaw and Bekar, 2005). In this emerging new era, greater technological opportunities can be found in other sectors. Electronics and hardware producers may be regarded as the high-opportunity mass production manufacturers of the present age. In their dynamic trajectory, these sectors have also sustained the rise of advanced knowledge providers (software and technical consultancy) and of network infrastructure services (telecommunications). It is the exchange of advanced knowledge, goods and services among these high-opportunity 
manufacturing and service sectors that accounts for the bulk of the growth potential in the current era (Laursen and Meliciani, 2002; Guerrieri and Meliciani, 2005).

In short, the specific key industries driving the growth of the economy will differ in any given historical age, but the overall causation mechanism that sustains the dynamics of the system remains, by and large, the same. A new GPT (or a new set of interrelated GPTs) will need to be produced on a large scale, supported by an efficient

infrastructure and sustained by the provision of an advanced knowledge base. Our model provides a comprehensive framework that accounts for the dynamics of a national system within each paradigmatic phase, as well as for the transformations that occur when a regime shift changes the locus of technological opportunities.

\section{Hypothesis 1: Growth and structural change in the long run}

In the transformation from the Fordist to the ICT-based age, industrial sectors that are closer to the production and use of the new GPTs have progressively improved their productivity performance, whereas the other sectoral groups have experienced a less dynamic trend.

In particular, our model points out a process of competition between an old and a new GPT in the two intermediate goods and service producers macro-sectors, namely the mass production goods producers (MPG) and the supporting infrastructure services (SIS) branches. Our first hypothesis therefore specifically argues that the new-GPT intermediate sectors (science-based manufacturing and network infrastructures services) have improved their productivity performance over time, whereas the corresponding old-GPT intermediate sectors (scale-intensive manufacturing and physical infrastructure services) have slowed down their productivity trend.

This first hypothesis naturally leads to ask what the main determinants of sectoral growth are. If it is indeed the case that industrial sectors more closely related to ICT activities have experienced a more dynamic performance in recent years, our model argues that this has to do with the greater set of technological opportunities that have recently been available to them, and with their superior ability to recognize and exploit them. More precisely, the model's properties pointed out above lead to formulate the following propositions. 


\section{Hypothesis 2: The determinants of sectoral performance}

2A. The growth of industrial sectors depends on (i) their ability to produce new technologies and (ii) their capability to acquire and use advanced technologies that have been produced in other industries.

2B. The impact of these two factors on productivity growth, however, differs substantially among the various sectoral groups pointed out by our model - because these groups are characterized by distinct technological capabilities, different abilities to acquire external knowledge and diverging productivity trends.

Hypothesis 2A has previously been investigated by a rich empirical literature on sectoral innovation, R\&D spillovers and productivity growth (Castellacci, 2008b). We now reinterpret this relationship within a GPT model context. It is important to highlight it explicitly here, since our theoretical model rests on the validity of this general proposition. Hypothesis $2 \mathrm{~B}$ is a more specific and more novel proposition. It qualifies the general proposition $2 \mathrm{~A}$ by taking into explicit account cross-sectoral differences in the innovation-performance relationship, which is an aspect that has not been adequately taken into account by previous empirical studies in the field.

The implications of these theoretical properties for the long-run dynamics of national economies have been briefly pointed out above, and lead to formulate our third testable hypothesis. Hypothesis 1 would imply that countries that manage to transform their industrial structure towards high-opportunity new GPT-related sectoral groups would experience a more dynamic aggregate performance (Peneder, 2003). Further, given the existence of a web of vertical linkages among industries, a specialization pattern in advanced manufacturing industries may foster the development of new services, and the latter may in turn act to enhance the growth of the former. A key mechanism of dynamics of a national system is thus related to the ability of a country to undertake a process of structural change from traditional to high-opportunity industries. Hypothesis 2, in addition, implies that the productivity dynamics of a national economy is also related to the overall innovative ability of the industrial system as well as the intensity of inter-sectoral linkages between different types of sectoral groups within the domestic economy. We summarize the country-level implications of our taxonomic model by means of the following proposition. 


\section{Hypothesis 3: National dynamics and cross-country differences}

National economies differ in their ability to exploit the opportunities provided by the ICT revolution. Country-level productivity growth is positively related to the four main factors highlighted by our model: (i) the ability of a country to undertake a process of structural change from traditional to ICT-related industries; (ii) the overall innovative ability of its industrial system; (iii) the overall ability to acquire external knowledge; (iv) the maximum level of productivity that can be achieved by a GPT, which is in turn shaped by a set of country-specific socio-institutional factors.

\section{Hypothesis 1: Growth and structural change in the long run}

The first property of our theoretical model focuses on the process of growth and structural change in the long run. Since the beginning of the 1990s, the rise and diffusion of a new set of GPTs related to ICTs has induced a transformation in the technological opportunities and economic dynamics of industrial sectors in advanced countries. Our model argues that sectors that are closer to the production and use of the new GPTs have progressively improved their economic growth performance, whereas the other groups have experienced a less dynamic trend.

In order to investigate the empirical relevance of this hypothesis, we consider the productivity performance of manufacturing and service industries in 18 OECD countries in the period 1970-2005. This is a relatively long period, which makes it possible to analyse whether a process of structural change and industrial transformation has effectively taken place in the shift from the end of Fordism (1970s and 1980s) to the rise of the new ICT-based age (the 1990s onward).

We make use of the EU KLEMS database, a novel dataset that provides data on labour productivity and other indicators for industrial sectors (2-digit level) for all manufacturing and service industries (EU KLEMS Database, March 2008; see Timmer et al., 2007; O'Mahony and Timmer, 2009). ${ }^{7}$ The database provides very rich information and can be analysed as a panel, since each industrial sector is observed in 18 different OECD countries for the period 1970-2005 (annual observations).

\footnotetext{
${ }^{7}$ Castaldi (2008) has recently made use of this new dataset and analysed cross-country differences in labour productivity by making use of shift-share analysis. Her methodology and results are interesting and relevant to complement the analysis that is undertaken in this section.
} 
Table 1 presents the labour productivity growth trends of the various sectoral groups highlighted in our model (average of 2-digit industries for each group ${ }^{8}$ ). The first row refers to the whole period 1970-2005, while the second and third rows refer to the two sub-periods of equal length 1970-1987 and 1988-2005 respectively. The table also reports the results of ANOVA tests for differences between the two sectoral groups belonging to each macro-sector. These ANOVA tests are in (nearly) all cases significant, thus indicating that the two industry groups within each macro-sector have on average experienced a different trend of labour productivity over time.

In the period 1970-1987, which may roughly be considered as the concluding phase of the Fordist age, the sectoral groups characterized by the most dynamic productivity growth were advanced knowledge providers manufacturing (AKP-M), mass production goods, both science-based and scale-intensive (MPG-SB and MPG-SI), supplier dominated manufacturing (PGS-M) and, to a less extent, physical infrastructure services (SIS-P). This pattern corresponds well to the sectoral description of the Fordist paradigm provided by Pavitt's (1984) taxonomy. By contrast, in the period 1988-2005, the initial phase of the ICT-based age, the most dynamic groups have so far been advanced knowledge providers manufacturing (AKP-M) and mass production goods science-based (MPG-SB).

Interestingly, looking at the changing pattern of each sectoral group between the two sub-periods, we observe that the groups that have experienced the most remarkable increase of productivity growth have been science-based manufacturing (MPG-SB) and network infrastructure services (SIS-N), which are those that our model has previously labelled as new GPT sectors. By contrast, the productivity performance has slowed down considerably for the groups of advanced knowledge providers (AKP-M and AKP-S), scale intensive (MPG-SI) and personal goods and services (PGS-M and PGS-S). On the whole, the aggregate productivity performance of OECD economies has slowed down in the shift from the first to the second sub-period (see last column of table 1). One possible interpretation of this pattern is that the second sub-period roughly corresponds to the initial phase of the new ICT-based age, which has not yet reached its full productivity potential. ${ }^{9}$

\footnotetext{
${ }^{8}$ The list of 2-digit industries considered in each sectoral group is reported in Appendix 1.

${ }^{9}$ An important industry taxonomy previously developed in the literature is the one that focuses on sectoral differences in the production and use of ICTs (e.g. O'Mahony and van Ark, 2003). This distinguishes three types of sectors: ICT-producing, ICT-using and non-ICT. It is interesting to compare the labour productivity growth of these sectoral branches with those presented in table 1 for
} 
We now analyse the same productivity pattern by exploiting the panel structure of the dataset. We carry out a test that is based on the analysis of a dynamic panel model where the labour productivity of each sector in a given period is regressed on its value in the previous period and a time trend. The test is derived as follows:

$\mathrm{LP}_{i, j, t}=\rho \mathrm{LP}_{i, t-1}+\lambda_{i}+\gamma_{j}+\delta_{\mathrm{t}}+\varepsilon_{i, j, t-1}$

where $\mathrm{LP}_{i, j, t}$ is the level of labour productivity of sector $i$ in country $j$ in period $t, \lambda_{i}$ represents a set of sector-specific effects, $\gamma_{j}$ a set of country-fixed effects, and $\delta_{\mathrm{t}}$ is a time trend. By first-differencing equation (24), we remove the secor- and countryspecific effects and obtain the following dynamic specification:

$\Delta \mathrm{LP}_{i, j, t}=\rho \Delta \mathrm{LP}_{i, t-1}+\Delta \delta_{\mathrm{t}}+\Delta \varepsilon_{i, j, t-1}$

The parameter $\rho$ represents the speed of convergence of each sector to its long-run trend, wheras the term $\Delta \delta_{\mathrm{t}}$ represents the time trend. The rationale of this exercise is to decompose the productivity growth of each sector into two parts: (1) the time trend component (which is the coefficient of our main interest) and (2) the convergence component, i.e. the extent to which each sector converges to its long-run growth path (which is less relevant in the context of the hypothesis that we are investigating here). We estimate equation (25) by making use of Arellano and Bond (1991) GMM estimator. The advantage of this method is twofold. First, since it is derived from a fixed effect model, it considers the omitted variable bias by including a full set of sector- and country-specific effects. Secondly, it takes into account the possible endogeneity of the explanatory variables by using as instruments their lagged values.

We estimate each sectoral group of the taxonomy separately in order to analyse the extent to which the labour productivity dynamics differs across the groups. We also

our taxonomy groups. Considering the two sub-periods defined in table 1, the ICT-producing sectors have remarkably increased their productivity growth from $5.7 \%$ to $7.3 \%$; ICT-users have slightly increased it from $2.2 \%$ to $2.4 \%$; whereas non-ICT industries have experienced a productivity slowdown from $3.1 \%$ to $2.2 \%$. On the whole, these results are largely consistent with those presented in table 1 : both taxonomies point to a process of structural change where ICT-related industries have improved their productivity performance over time whereas other sectors have gradually slowed down. 
report the results for the two sub-periods 1970-1987 and 1988-2005, in order to investigate differences in the working of the model between the end of Fordism and the beginning of the new ICT-based age. The results are reported in table 2.

\section{$<$ Table 2 here $>$}

In the first sub-period, the time trend indicates that productivity growth has been faster for advanced knowledge providers manufacturing (AKP-M), science-based (MPG-SB) and supplier dominated manufacturing (PGS-M). In the second subperiod, the productivity growth trend is particularly rapid for the group of sciencebased manufacturing (MPG-SB), which is in fact the bunch of sectors that registers the greatest change from the first to the second period. These panel regression results are on the whole consistent with the descriptive evidence on productivity growth averages presented above.

In summary, the empirical evidence presented in this section provides basic support for the first of our theoretical hypotheses. If we look at the growth of labour productivity of manufacturing and service industries in the OECD area in the last 35year period, we observe that a visible process of structural change and industrial transformation is at stake. The sectoral groups that are typically considered to be closer to the production and use of the new GPTs have progressively improved their productivity growth performance over time (MPG-SB, SIS-N), whereas some of the other (older GPT) groups have gradually decreased their contribution to the aggregate productivity growth pattern (particularly MPG-SI, PGS-S, PGS-M).

There are however some of the sectoral groups whose productivity dynamics does not fully correspond to the predictions of our GPT model. First, physical infrastructure services (SIS-P) have not decreased their productivity growth rate in the shift from the first to the second sub-period, whereas the model presented in section 2 would suggest this sectoral group to gradually loose momentum and slow down over time. Secondly, advanced knowledge providers (both AKP-M and AKP-S) have experienced a visible decrease in their productivity growth trends, while our model would suggest that these sectoral groups should increase their productivity performance over time since they are closer to the core of the new set of GPTs. A reasonable interpretation of these patterns is however that the second sub-period (1988-2005) only refers to the initial 
phase of the new paradigmatic phase, and that the diffusion of the latter and its full productivity potential will only be reached in a longer time frame. ${ }^{10}$

\section{Hypothesis 2: The determinants of sectoral performance}

The evidence presented in the previous section focused on the trend of labour productivity of manufacturing and service industries, but it did not investigate the determinants of the observed process of structural change. Based on our GPT model, the previous section simply interpreted this productivity dynamics as a manifestation of a process of transformation brought about by the rise of the new ICT-related GPTs. Our second hypothesis analyses this assumption more carefully by investigating the main determinants of the productivity performance of industrial sectors.

We investigate this second hypothesis by means of two distinct exercises. The first focuses on the role of human capital and ICTs for the productivity performance of industrial sectors in the period 1991-2005 (panel data setting). The second analyses the relationships between innovation, vertical linkages and sectoral dynamics in the more recent period 2002-2005 (cross-sectional data).

\subsection{The role of human capital and ICTs}

When we focus on the period 1991-2005, the EU KLEMS dataset briefly described in the previous section makes it possible to analyse the relationships between sectoral productivity performance, human capital and ICTs in a panel data framework, since information for each sector is recorded annually for the whole period. The panel comprises a total of 4565 observations, i.e. each manufacturing and service industry (2-digit level) in each of the 18 countries of this OECD sample is observed annually for the whole period.

\footnotetext{
${ }^{10}$ We have also carried out some additional estimations of this model in order to see whether the results described here still hold when we vary the length of the two sub-periods. Specifically, we have repeated the estimations of equation (25) for ten different periodizations, i.e. varying the time break between the two sub-periods from the year 1983 to the year 1993. The results of these additional regressions (available on request) are largely in line with those presented in table 2. However, this robustness exercise also indicates an interesting pattern: when we shorten the length of the second subperiod, there are other sectoral groups that also show a positive change in the estimated trend over time, and among them AKP-M and AKP-S. This would corroborate the idea pointed out above that the diffusion and full productivity potential of a new technological paradigm develops gradually over time, so that its emergence is more visible when we focus on a shorter (more recent) period.
} 
The reason for focusing on ICT and human capital as the two main determinants of sectoral productivity growth is that these variables represent two important dimensions of the process of sectoral growth and the diffusion of the new GPTs (van Ark et al., 2008). The ICT indicator (ICT capital service per hour worked) is a direct measure of how close a sector is to the core of the new ICT-based GPTs and, more broadly, also an indicator of the industry's ability to acquire and make use of ICT capital produced by other upstream sectors. The human capital variable is measured through the number of hours worked by high skilled persons engaged (share in total number of hours worked). This may reasonably be considered a useful indicator of the technological capability of industrial sectors, which is an important determinant of sectoral productivity growth according to the model presented in section $2 .^{11}$

The specification and estimation method we make use of are the same pointed out in the previous section. Equation (25), augmented with the two explanatory variables ICT (ICT capital) and HK (human capital), becomes:

$\Delta \mathrm{LP}_{i, j, t}=\rho \Delta \mathrm{LP}_{i, t-1}+\eta \Delta \mathrm{ICT}_{i, j, t-1}+\psi \Delta \mathrm{HK}_{i, j, t-1}+\Delta \delta_{\mathrm{t}}+\Delta \varepsilon_{i, j, t-1}$

This equation is estimated again in a dynamic panel model setting by means of Arellano and Bond GMM estimator. Table 3 presents the regression results. The first column reports the estimations of the base version of the model as specified in equation (26). The other columns investigate differences in the working of the model across the sectoral groups of the taxonomy by adding slope dummies (SD, i.e. dummies in multiplicative form) to both the ICT and the human capital variables for each industry group.

The base version of the model provides support for our general hypothesis that the performance of industrial sectors in the emerging ICT age is increasingly dependent on two important factors: the ICT capital intensity of industries and their human capital (technological capability). Both variables are positively and significantly related to the dynamics of labour productivity in this large sample of manufacturing and service industries in OECD countries. The other eight columns of table 3 refine this general result, and support the idea that the determinants of sectoral dynamics

\footnotetext{
${ }^{11}$ An additional reason for focusing on these two indicators is that no other variable measuring technological capabilities and/or inter-sectoral knolwedge diffusion is available in panel form in the EU KLEMS dataset.
} 
vary substantially across the various taxonomy groups (see hypothesis $2 \mathrm{~B}$ ). All the slope dummies variables included in these regressions are in fact significant at conventional levels, indicating that the estimated coefficients of both the ICT and human capital variables differ among the sectoral groups. ${ }^{12}$

In particular, the effect of the ICT capital variable on labour productivity growth turns out to be stronger for the groups of scale intensive manufacturing (MPG-SI), physical infrastructure services (SIS-P) and supplier-dominated goods producers (PGS-M). This is an interesting finding, and may be related to the exploitation of scale economies that the use of ICTs makes it possible to achieve in sectoral groups producing standardized products and services (Castaldi, 2008). These high estimated elasticities thus suggest that a more rapid diffusion of information technologies in less technologically advanced branches of the economy may be of great benefit to regenerate technological and economic opportunities in these mature sectors.

On the other hand, when we look at the effect of the human capital variable on productivity dynamics, this turns out to be particularly strong for the bunch of science-based and scale-intensive mass production producers (MPG-SB and MPGSI), indicating that the availability of high-skilled labour is a particularly crucial growth engine for business environments characterized by a complex knowledge base and the need to coordinate large-scale operations. By contrast, the human capital variable turns out to be negative for all the service industry groups of our model (AKP-S, SIS-N, SIS-P, PGS-S). This is an interesting finding that would call for further future research, since it contrasts with the statement frequently made in the recent service innovation literature that human capital is a more important factor for the performance of the service sectors than for manufacturing (e.g. Drejer, 2004).

These findings on the role of the human capital variable are however not conclusive and should be interpreted with caution. In order to have a more precise assessment of the relationships between technological capability, vertical linkages and sectoral productivity growth, we need to consider a broader set of innovation-related factors.

\section{$<$ Table 3 here $>$}

\subsection{The role of innovation and vertical linkages}

\footnotetext{
${ }^{12}$ When a slope dummy (SD) is included in the regression model, the estimated coefficient of a given sectoral group is the algebraic sum of the overall estimated coefficient and the one for the SD.
} 
In this second exercise, in addition to the ICT and human capital variables, we want to take into consideration a broader range of indicators measuring the ability to innovate of each sector as well as its capability to imitate advanced technologies produced in other branches of the economic system. In order to carry out this more comprehensive analysis, we focus on the recent period 2002-2005 and combine information from the EU KLEMS dataset with data from the Fourth Community Innovation Survey (CIS4). The latter provides a rich set of information on the innovative activities of manufacturing and service industries in a large sample of European countries. By combining the two data sources, we obtain a cross-section of industries (2-digit level) for a sample of around 20 European countries, comprising around 300 observations.

Differently from the panel analysis previously undertaken, the cross-sectional nature of the matched EU KLEMS-CIS4 dataset does not enable to take into adequate account the possible problems of endogeneity caused by the dynamic interactions between innovation and productivity. However, the advantage of this second exercise is that we now have availability of a much richer set of information on innovation and vertical linkages that was not available in the test presented in section 4.1.

In this short-run cross-sectional sample, we investigate the relationships between the growth of labour productivity of each sector (average annual growth in the period 2002-2005; source: EU KLEMS) and a set of explanatory variables related to the innovation characteristics of the industry, i.e.: (1) its innovation output; (2) its innovative strategies and technological trajectories; (3) the vertical linkages and external sources of technological opportunities (source: CIS4). ${ }^{13}$

The results of OLS estimations of the base version of the model are presented in table 4. The table indicates that all of the explanatory variables included in the regressions are significantly related to the sectoral dynamics. The three sets of explanatory factors, innovation output, innovative strategies and vertical linkages, are gradually inserted in the model. Regression (4) includes them all, and points out their relevance and statistical precision in a cross-sectional setting. Innovation output (turnover from

\footnotetext{
${ }^{13}$ For a definition of the indicators, see Appendix 2. Ideally, it would have been appropriate to measure sectoral technological capabilities by means of innovation input indicators (e.g. R\&D or total innovation intensity). However, the time span considered here is rather short, and does not enable a proper investigation of the long-run link between innovation input, output and productivity performance. Therefore, in these cross-sectional regressions we prefer to focus on the link between innovation output and productivity, which is a more reasonable object of study in the context of this short-run cross-sectional sample. For a related exercise exploring the relationships between technological regimes and sectoral productivity growth based on CIS2 data, see Castellacci (2007).
} 
novel products, process innovations and organizational innovations) is positively related to the growth of productivity of each industry. Innovative strategies (export orientation, $\mathrm{R} \& \mathrm{D}$ orientation, acquisition of machinery and software, training expenditures) do also turn out to be relevant factors for the sectoral dynamics.

Last, vertical linkages and external sources of opportunities are also significantly related to the dependent variable. The interactions with the suppliers and the competitors are positively related to the productivity performance of sectors, confirming the importance of advanced knowledge acquired from upstream sectors as predicted by our GPT model. By contrast, users and Universities turn out to be negatively linked to productivity growth. This finding is apparently in contrast with the emphasis usually given to this type of external sources in the innovation literature. However, it should be emphasized the short-term nature of the sample analysed here, and it could be reasonable to expect that users-producers and science-based interactions may turn out to be more relevant growth engines in a longer time frame.

Taken together, tables 3 and 4 provide basic empirical support for the hypothesis that the growth of industrial sectors are related to the main factors highlighted by our GPT model: technological capabilities and vertical linkages (see hypothesis 2A). However, the model also suggests that these factors differ substantially across sectors, and so does their relationship to sectoral productivity growth (see hypothesis $2 \mathrm{~B}$ ). Tables 5 and 6 seek to provide empirical evidence to investigate this more specific proposition. Table 5 presents some descriptive evidence on the explanatory variables that we have previously made use of. The table reports the average of the various indicators for each sectoral group, as well as a set of ANOVA tests to investigate mean differences within each macro-sector. Two interesting indications may be drawn from this empirical evidence. The first emerges when we compare the four macro-sectors between them. The advanced knowledge providers (AKP) and mass production goods producers (MPG) are on average characterized by a greater technological capability than the other two macro-sectors, as indicated for instance by their higher turnover from novel products and greater R\&D orientation. By contrast, the supporting infrastructure services (SIS) and personal goods and services (PGS) macro-sectors have a higher propensity to acquire embodied knowledge by interacting with their suppliers rather than creating new products and processes internally. This is in fact what depicted in the diagram in figure 1, where the former (latter) two groups are positioned on the right-hand (left-hand) side of the technological capability (X) axis. 
The second indication that we get from table 5 is obtained by comparing the two sectoral groups within each macro-sector (see results of ANOVA tests). In particular, in the MPG macro-sector, science-based industries (that our model has for simplicity labelled the new GPT group) are characterized by a higher technological capability (innovation output and R\&D orientation) than scale intensive sectors (that is our model's old GPT group). A similar pattern emerges when we compare the technological capability of network infrastructure services (SIS-N) and physical infrastructure services (SIS-P). In short, this cross-sectional evidence corroborates our model's assumption that technological capabilities and opportunities are higher in sectors that are closer to the production and use of the new GPTs (i.e. $\beta_{\mathrm{MPG}-\mathrm{SB}}>\beta_{\mathrm{MPG}}$ SI and $\beta_{\text {SIS-N }}>\beta_{\text {SIS-P, }}$ see section 2.1). ${ }^{14}$

To what extent do these cross-sectoral differences affect the productivity performance of the various sectoral groups? Table 6 presents the results of model specifications that include slope dummies for some of the variables and some of the sectoral groups. ${ }^{15}$ The inclusion of dummies in multiplicative form, as previously pointed out, seeks to analyse the extent to which the effect of the explanatory variables differ across the sectoral groups of the GPT model. Several slope dummy variables turn out to be significant in the regressions. We point out three of them, which appear more interesting in the light of innovation theory. First, the turnover from the commercialization of novel products has a stronger impact on productivity for science-based sectors (MPG-SB), but it is less relevant for advanced knowledge providers services (AKP-S), since these are more oriented to the creation of knowledge-intensive services rather than high-tech capital goods. Secondly, the acquisition of machinery and software from other sectors turns out to be a more relevant growth strategy for scale-intensive (MPG-SI) and network infrastructural services (SIS-N), because these make greater use of this embodied type of innovation trajectory. Thirdly, user-producer interactions have a stronger estimated effect for advanced knowledge providers services (AKP-S) and a smaller coefficient for

\footnotetext{
${ }^{14}$ As explained in section 2, our model's choice of distinguishing between new GPT groups (MPG-SB and SIS-N) and old GPT groups (MPG-SI and SIS-P) is made for simplicity of exposition. The empirical evidence presented here has instead a more realistic interpretation: the industries in the new (old) GPT groups, which are typically pointed out in the literature as being closer (more distant) to the production and use of ICTs, are shown to have a higher (lower) level of technological opportunities.

${ }^{15}$ Initially, slope dummies have been included for all the regressors and all sectoral groups. However, in the final model specifications presented in table 6 , only the slope dummies that turn out to improve the explanatory power of the model have been retained.
} 
network infrastructural services (SIS-N), since the former typically work in close collaboration with their clients (so called customisation; see Evangelista, 2000), while the latter are more dependent on their suppliers for the acquisition of advanced machineries and software.

In summary, the results presented in this section provide empirical support for the second hypothesis put forward by our theoretical model. Both the panel and the crosssectional evidence indicate that (1) the growth of industrial sectors increasingly depends on human and ICT capital, innovation and vertical linkages (hypothesis 2A), and that (2) the relevance and impact of these factors differ substantially among the various groups outlined by our GPT model (hypothesis 2B).

\section{$<$ Tables 4, 5 and 6 here $>$}

\section{Hypothesis 3: National dynamics and cross-country differences}

What are the implications of this sectoral dynamics for the aggregate performance of national economies? It is reasonable to assume that countries differ in their ability to exploit the opportunities provided by the emergence and diffusion of the ICT-based age. More specifically, given the process of structural change and the underlying determinants pointed out in the previous sections, the natural country-level implication would be that the growth performance of each national economy is positively related to three main factors: (1) the overall innovative ability of each country; (2) its capability to acquire external knowledge; (3) the ability to undertake a process of structural change from traditional to ICT-related (new GPTs) manufacturing and service industries. ${ }^{16}$

In order to investigate this third hypothesis, we carry out one conclusive exercise. We consider again our sample of OECD countries and estimate the (aggregate) relationship between their GDP per capita growth and the three explanatory factors highlighted by the GPT model (in addition to a set of other customary control

\footnotetext{
${ }^{16}$ The model presented in section 2 also highlighted a fourth factor to explain cross-country growth differences, i.e. the maximum level of productivity that can be achieved by a GPT in each country. This factor is in turn shaped by a large set of socio-institutional factors specific to each country, and its multifaceted nature makes it difficult to measure it properly in empirical analyses. Our cross-country regression analysis will therefore include this fourth factor in the set of country fixed effects.
} 
variables). We make use of country-level data from the Penn World Tables and the World Bank's World Development Indicators for the period 1980-2005. These data are available as a panel (five sub-periods each composed of a 5-year interval), so that we are able to adopt again a dynamic panel model estimation method (Arellano and Bond GMM) in order to take into account possible problems related to the omitted variable bias and the endogeneity of the regressors. We include the following set of explanatory variables (for the definition and source of indicators see Appendix 2):

- GDP per capita (lagged), a measure of the speed of convergence of each country to its long-run path;

- Physical capital (investment as a share of GDP);

- Human capital (number of years of higher education);

- ICT exports (ICTs exports as a share of commercial service exports), a measure of the ability of countries to produce ICT products and services and sell them in international markets;

- Patents per capita, a measure of the overall innovative ability of countries. This is therefore a synthetic measure of the vector $\boldsymbol{\beta}_{i}$ (see equation (23));

- Mobile telephony (number of mobiles per thousand people), which is an indicator of ICT infrastructures and, more generally, of the intensity of connections among economic agents within a national system. We use it as a measure of the overall ability to acquire external knowledge, i.e. a proxy measure for the vector $\boldsymbol{\theta}_{i}$ (see equation (23)); ${ }^{17}$

- Employment shares of the eight sectoral groups of our GPT model (calculated from the EU KLEMS database used in the previous sections). This set of variables provides a measure of the facility for structural change, i.e. the vector $\boldsymbol{\alpha}_{i}$ pointed out in equation (23) of the model. ${ }^{18}$

\footnotetext{
${ }^{17}$ The indicator used here is admittedly far from perfect. Ideally, vertical linkages and the intensity of knowledge diffusion should be measured by more specific innovation-related indicators, e.g. obtained from input-output tables or from innovation surveys data (as the indicators we have used in the crosssectional analysis in section 4.2). However, these more specific indicators are only available in crosssectional form and for a more recent period only, and we are therefore unable to use them in the longerperiod dynamic panel analysis that is presented in this section.

${ }^{18}$ In the model presented in section 2.1, the vector $\boldsymbol{\alpha}_{i}$ referred to the macro-sectors MPG and SIS only. In the regression analysis presented here, however, we provide a more flexible specification according to which all the sectoral groups are allowed to have a different structural change parameter.
} 
The first six variables in the regression model are expected to be positive in the estimations. Regarding the last set of variables (employment shares), our model would suggest a positive (negative) sign for those sectoral groups that our model has labelled new (old) GPT groups, since a shift of resources towards (away from) these industries would increase (decrease) the overall productivity of the economic system. The results of dynamic panel estimations are presented in table 7 . We report results for two periods, a longer (1980-2005) and a shorter (1990-2005) time span. By comparing the results in columns 1,2 and 3 with those reported in columns 4, 5 and 6 respectively, we may thus investigate whether the observed patterns are stable or changing over time (the shorter period considered here corresponds to the rise of ICT period that we have considered and discussed in the previous sections).

The physical capital variable is always positive and significant, and its estimated coefficient is stable over time. The human capital variable does also turn out to have a positive and stable coefficient, although it is not statistically significant in most of the regressions presented in table 7 (this is a well-known common result in the applied convergence literature). The ICT export variable is positive, stable over time and always statistically significant. It indicates that the ability of advanced countries in the OECD area to produce ICT products and services and sell them in international markets is an important factor to boost their aggregate dynamics.

The innovation (patents) variable is also positive and significant in all the regressions. Interestingly, the size of its estimated coefficient is substantially larger in the regressions referring to the more recent period 1990-2005, thus suggesting that the overall innovative ability of countries has become an increasingly important factor in the more recent period characterized by the rise and diffusion of ICT-based GPTs. The mobile telephony variable, only available in the shorter time span regressions, takes the expected positive sign, although the precision of the estimates is low in columns 5 and 6 . This variable therefore provides moderate but not conclusive support for the hypothesis that the intensity of knowledge diffusion matters for the aggregate performance of national economies. ${ }^{19}$

\footnotetext{
${ }^{19}$ As previously noticed, the telephony variable is arguably not a good proxy for the intensity of knowledge diffusion. A better measure would for instance be the intensity of innovation cooperation (source: CIS4), which is however available only in cross-sectional form and cannot therefore be used in our panel regressions. Interestingly, the Spearman's rank correlation coefficient between the innovation cooperation variable (in CIS4 data) and aggregate productivity growth in this cross-sectional sample of OECD countries is positive and high (+0.745, in the period 2002-2005). This provides further support for the positive relationship between sectoral linkages and the aggregate dynamics of productivity.
} 
Finally, the employment shares variables reported in the lower part of table 7 provide interesting indications regarding the relationship between the process of structural change at the industry-level and productivity dynamics at the country-level (Peneder, 2003). We first include in the regression model the employment shares variables for all of the eight sectoral groups (see columns 2 and 5); we then exclude some of them, and retain only the sectoral groups that are typically considered to be more closely related to the new GPTs, in order to analyze the extent to which these are important growth factors (see columns 3 and 6).

Let us first look at the advanced knowledge providers macro-sector, whose employment shares variables do not behave as expected by our model. In fact, for the specialised suppliers manufacturing industries (AKP-M) we do not find any significant relationship between their employment share and the aggregate performance of national economies, whereas for advanced knowledge providers services (AKP-S) the estimated coefficient is actually negative and significant. This finding is interesting but somewhat puzzling, since advanced knowledge providers are typically expected to play an important function in the modern knowledge-based economy, and we would have therefore expected that economies that employ a greater share of resources in these sectors should experience a more dynamic performance. This is a pattern that is related to the stagnant performance experienced by this industry group in the last few years (previously pointed out at the end of section 3), and that deserves further attention in future research.

Shifting the focus to the mass production goods producers macro-sector, the sciencebased (MPG-SB) sectoral group turns out with a positive estimated coefficient, which is larger (and more statistically significant) in the shorter time span regressions (see column 6). This confirms our model's suggestion that the role of science-based industries has become more prominent since the rise of the ICT-based age. Analogously, in the supporting infrastructure services macro-sector, the group of network infrastructure services (SIS-N) has a positive and significant estimated coefficient. The size of this estimated coefficient is much higher than those of all the other sectoral groups, and it increases substantially in the regressions reported in columns 5 and 6 , i.e. those referring to the more recent period.

Finally, with respect to the personal goods and services macro-sector (PGS), the employment shares of both sectoral groups belonging to it are negatively related to country-level GDP per capita growth. These negative signs are also in line with our 
model, as they indicate that countries that have progressively decreased their shares in these traditional industries (PGS-M and PGS-S) have grown more rapidly.

In summary, these regression results corroborate our third hypothesis and indicate that the productivity performance of advanced countries is positively related to the three main factors emphasized by our GPT model: (1) the innovative ability of its industrial system; (2) the intensity of knowledge diffusion; (3) the ability of each country to undertake a process of structural change from traditional to ICT-related manufacturing and service industries, and particularly the network infrastructure services (SIS-N) and the science based manufacturing (MPG-SB) sectoral groups.

\section{$<$ Table 7 here $>$}

\section{Conclusions}

The paper has put forward and empirically investigated a GPT model of structural change and the growth of industrial sectors. The model identifies various groups of manufacturing and service industries that differ in terms of their technological capability and the function they assume in the economic system. Since sectoral groups differ, the model argues that the channels and the extent to which they contribute to the dynamic performance (productivity) of the system will also be substantially different. The empirical analysis has therefore investigated the patterns and determinants of the process of structural change by focusing on the growth of labour productivity of manufacturing and service industries in a sample of 18 OECD countries in the period 1970-2005. The empirical test of the GPT model has analysed three main hypotheses, and the results can be summarized as follows.

First, we have found clear evidence of a process of structural change that has taken place in the OECD area over the period 1970-2005. In the shift from the end of Fordism to the beginning of the new ICT-based age, sectoral groups that are closer to the core of the new GPTs have visibly improved their productivity performance, whereas other more traditional industries have experienced a more stagnant trend (hypothesis 1).

Secondly, investigating the possible determinants of the sectoral productivity dynamics in a more recent period, we have highlighted some major factors that are 
positively related to the growth of industrial sectors, and in particular (1) their technological capability (measured by their human capital, innovation output, innovation strategies and trajectories) and (2) their ability to acquire external knowledge from other industries (measured by the intensity of inter-sectoral linkages and the intensity of use of ICT capital). We have also found that the effects of these factors on the productivity dynamics differ substantially across the sectoral groups outlined by the model (hypothesis 2).

Thirdly, shifting the focus to the aggregate (country-level) implications of the model, we have presented evidence in support of the idea that the long-run performance of national economies is positively related to three main factors: (1) their overall level of innovative capability, (2) their intensity of external knowledge acquisition, and (3) their ability to undertake a process of structural change towards high-opportunity sectoral groups, and particularly science-based manufacturing and network infrastructure services (hypothesis 3).

These three results provide encouraging empirical support for our GPT model, and lead to two major implications. The first is that the industrial structure and specialization profile of an economy matter for its long-run performance. In any given historical period, the emergence and diffusion of general-purpose technologies provide a new set of technological opportunities, and industrial sectors greatly differ in their ability to exploit these opportunities and transform them into productivity gains. Countries that are able to rapidly shift their industrial structure towards the high-opportunity sectors of a given age can experience a more dynamic performance. The reason is twofold: first, because these sectors are characterized by greater technological capabilities and innovative ability; secondly, because they provide a stronger stimulus for the growth of the whole system through vertical linkages, intersectoral knowledge diffusion and the related spillover effects.

The second implication refers to the innovation policy dimension of these results. Different groups of manufacturing and service sectors assume a distinct function in the economic system and, relatedly, they are characterized by different technological capabilities, innovative strategies, external linkages and productivity performance. The focus on sectoral heterogeneity that has been emphasized throughout the paper questions the rationale of commonly adopted generic policies that target the R\&D and innovative intensity of firms without paying due attention to the sectoral context in which private enterprises operate. Innovation policy support must be specifically 
targeted to the set of characteristics, opportunities and constrains that firms face in different sectors of the economy.

\section{Acknowledgements}

The paper was presented at the workshop on Innovation and the International Competitiveness of Nordic Services, Oslo, May 2008, at the Globelics Conference, Mexico City, September 2008, and at a seminar at the Max Planck Institute of Economics, Jena, October 2008. I wish to thank Carolina Castaldi, Tommaso Ciarli, Mark Knell, Keld Laursen, Valentina Meliciani, Paolo Saviotti, Maria Savona, Jaider Vega, two anonymous referees and the Editor of this Journal for the very helpful comments and suggestions. The usual disclaimers apply.

\section{Appendix 1: List of industries in each sectoral group}

\section{AKP-S}

Advanced knowledge providers - Knowledge-intensive business services:

Computer and related activities; research and development; other business activities

\section{AKP-M}

Advanced knowledge providers - Specialized suppliers manufacturing:

Machinery and equipment; medical, precision and optical instruments

\section{MPG-SB}

Mass production goods - Science-based manufacturing:

Chemicals; office machinery and computers; electrical machinery and apparatus; radio, TV and communication equipment

\section{MPG-SI}

Mass production goods - Scale-intensive manufacturing:

Rubber and plastic products; other non-metallic mineral products; basic metals; fabricated metal products; motor vehicles; other transport equipment

\section{SIS-N}

Supporting Infrastructure Services - Network infrastructure:

Post and telecommunications; financial intermediation; insurance and pension funding; activities auxiliary to financial intermediation

\section{SIS-P}

Supporting Infrastructure Services - Physical infrastructure:

Wholesale trade and commission trade; land, water and air transport; supporting and auxiliary transport activities 


\section{PGS-M}

Personal goods and services - Supplier-dominated manufacturing:

Food and beverages; textiles; wearing; leather; wood and related; pulp and paper; printing and publishing; furniture; recycling

\section{PGS-S}

Personal goods and services - Supplier-dominated services:

Sales, maintenance and repair of motor vehicles; retail trade and repair of personal and household goods; hotels and restaurants

\section{Appendix 2: Data sources and indicators}

Industry-level data from the EU KLEMS Database (1970-2005)

- LP: Labour productivity: gross value added per hour worked, volume indices, $1995=100$

- ICT: ICT capital service per hour worked, reference 1995

- HK: hours worked by high skilled persons engaged (share in total hours)

Industry-level data from the Fourth Community Innovation Survey (2002-2004)

- Turnover from novel products: turnover from products that are new to the market, share of total turnover

- Process innovation: number of process innovators, share of total population of firms

- Organizational innovation: firms introducing organizational innovations, share of total population of firms

- Export orientation: firms exporting to other European countries, share of innovative firms

- R\&D orientation: Total R\&D expenditures, share of innovative costs

- Acquisition of machinery \& software: expenditures for the acquisition of machinery and software, share of innovative costs

- Training expenditures: firms engaged in training activities, share of innovative firms 
- External sources: Suppliers: firms considering their suppliers of equipment, materials, components or software as a very important source of information for their technological activities, share of innovative firms

- External sources: Users: firms considering their clients or customers as a very important source of information for their technological activities, share of innovative firms

- External sources: Competitors: firms considering their competitors in the same market as a very important source of information for their technological activities, share of innovative firms

- External sources: Universities: firms considering the universities or other public research institutes as a very important source of information for their technological activities, share of innovative firms

- Cooperation intensity: firms engaged in all types of cooperation in technological activities, share of innovative firms

\section{Country-level data used in section 5}

- GDP per capita: GDP per capita, PPPs, constant prices (log). Source: Penn World Tables (6.1)

- Physical capital: Investment as a share of GDP $(\log )$. Source: Penn World Tables (6.1)

- Human capital: Number of higher education years (log). Source: Barro and Lee (2001)

- ICT Exports: Computer, communications and other services as a share of commercial service exports. Source: World Bank (2007)

- Patents: Patents registered at the USPTO per million people $(\log )$. Source: USPTO (2002)

- Mobile telephony: Number of mobile phones per thousand people $(\log )$. Source: World Bank (2007)

- Empl (j): employment of the sectoral group $j$ as a share of total employment. Source: own calculations on the EU KLEMS database. 


\section{References}

Arellano, M. and Bond, S. 1991. Some tests of specification for panel data: Monte Carlo evidence and an application to employment equation. Review of Economic Studies 58, 277-297.

Ark, van B., M. O'Mahony and M.P. Timmer (2008). European Growth: the End of Convergence. Journal of Economic Perspectives, 22(1), 25-44.

Barro, R., and J. W. Lee. 2001. International Data on Educational Attainment: Updates and Implications. Oxford Economic Papers 53 (3), 541-563.

Bresnahan, T. and Trajtenberg, M. 1995. General purpose technologies: 'engines of growth'?. Journal of Econometrics 65, 83-108.

Carlaw, K. and Lipsey, R. 2006. GPT-driven endogenous growth. Economic Journal $116,155-174$.

Carlaw, K. and Lipsey, R. 2007. Sustained growth driven by multiple co-existing GPTs. Simon Fraser University Department of Economics Working Paper Series, dp 07-17.

Carlaw, K., Lipsey, R. and Webb. R. 2007. The past, present and future of the ICT revolution. Final Report, Research Project sponsored by Industry Canada.

Castaldi, C. 2008. The relative weight of manufacturing and services in Europe: An innovation perspective. Technological Forecasting and Social Change, in press.

Castellacci, F. 2007. Technological regimes and sectoral differences in productivity growth. Industrial and Corporate Change 16 (6), 1105-1145.

Castellacci, F. 2008a. Technological paradigms, regimes and trajectories. Manufacturing and service industries in a new taxonomy of sectoral patterns of innovation. Research Policy 37, 978-994.

Castellacci, F. 2008b. Innovation and the international competitiveness of industries: Comparing the mainstream and the evolutionary approaches. Technological Forecasting and Social Change, 75, 984-1006.

Drejer, I. 2004. Identifying innovation in surveys of services: a Schumpeterian perspective. Research Policy 33, 551-562.

Evangelista, R. 2000. Sectoral patterns of technological change in services. Economics of Innovation and New Technologies 9, 183-221.

Freeman, C., Clark, J., Soete, L. 1982. Unemployment and Technical Innovation. Pinter, London.

Freeman, C., Louça F. 2001. As Time Goes by: From the Industrial Revolutions to the Information Revolution. Oxford University Press, Oxford. 
Guerrieri, P., Meliciani, V. 2005. Technology and international competitiveness: the interdependence between manufacturing and producer services. Structural Change and Economic Dynamics 16, 489-502.

Hartwig, J. 2008. Productivity growth in service industries: Are the transatlantic differences measurement-driven? Review of Income and Wealth 54 (3), 494-505.

Helpman, E. and Trajtenberg, M. 1998. The diffusion of general purpose technologies. In Helpman, E. (Ed.) 1998. General Purpose Technologies and Economic Growth. MIT Press, Cambridge, MA.

Laursen, K., Meliciani, V. 2002. The relative importance of international vis-à-vis national technological spillovers for market share dynamics. Industrial and Corporate Change 11 (4), 875-894.

Lipsey, R., Carlaw, K., Bekar, C., 2005. Economic Transformations: General Purpose Technologies and Long-run Economic Growth. Oxford University Press, Oxford.

Miozzo, M., Soete, L. 2001. Internationalization of services: a technological perspective. Technological Forecasting and Social Change 67, 159-185.

O'Mahony, M. and van Ark, B. 2003. EU Productivity and Competitiveness: An Industry Perspective. European Communities, Luxembourg.

O’Mahony, M. and Timmer, M. 2009. Output, Input and Productivity Measures at the Industry Level: the EU KLEMS Database. Economic Journal, forthcoming.

Pavitt, K. 1984. Sectoral patterns of technical change: towards a taxonomy and a theory. Research Policy 13, 343-373.

Peneder, M. 2003. Industrial structure and aggregate growth. Structural Change and Economic Dynamics 14, 427-448.

Peneder, M. 2008. Entrepreneurship, technological regimes, and productivity growth. EU Klems Working Paper nr. 28.

Timmer, M., O'Mahony, M. and van Ark, B. 2008. The EU KLEMS Growth and productivity accounts: An overview. University of Groningen and University of Birmingham.

USPTO, United States Patent and Trademark Office 2002. Registered Patent Database. Washington, D.C.: USPTO.

World Bank 2007. World Development Indicators. Washington, D.C.: The World Bank. 
Figure 1: Production structure and the diffusion of GPTs

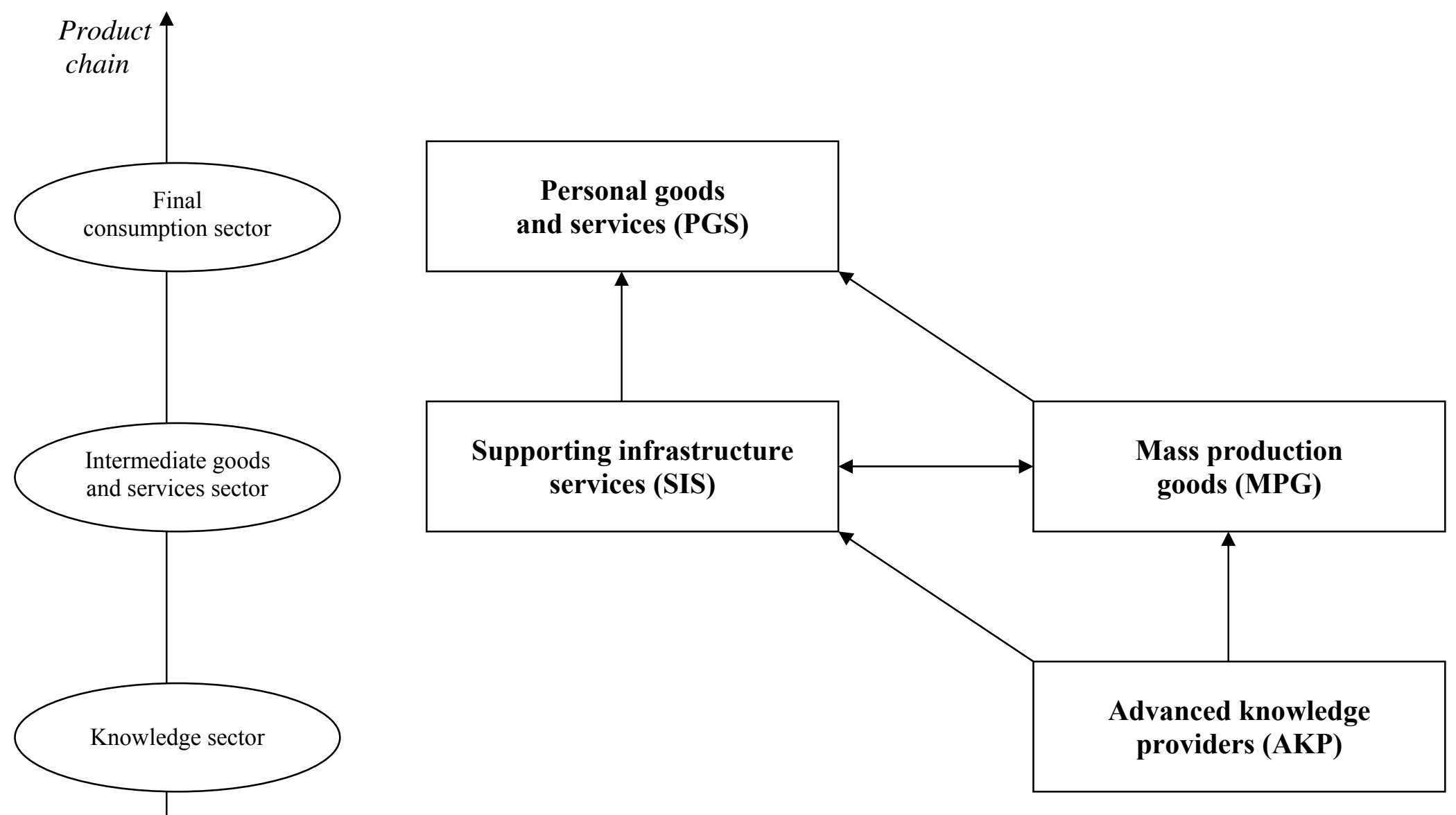


Table 1: Labour productivity growth of manufacturing and service industries (average annual growth rates), and ANOVA tests for differences within each sectoral group

\begin{tabular}{|c|c|c|c|c|c|c|c|c|c|}
\hline & AKP-M & AKP-S & MPG-SB & MPG-SI & SIS-N & SIS-P & PGS-M & PGS-S & Total \\
\hline $\begin{array}{c}\text { Whole period } \\
\text { (1970-2005) }\end{array}$ & \multicolumn{2}{|c|}{$(+9.03)^{* * *}$} & \multicolumn{2}{|c|}{$(+6.06)^{* * *}$} & \multicolumn{2}{|c|}{$(-3.33)^{* * *}$} & \multicolumn{2}{|c|}{$(+6.16)^{* * *}$} & $2.34 \%$ \\
\hline $\begin{array}{l}\text { First period } \\
(1970-1987)\end{array}$ & \multicolumn{2}{|c|}{$(+7.64)^{* * *}$} & \multicolumn{2}{|c|}{$(+5.47)^{* * *}$} & $\begin{array}{r}1.10 \% \\
(-3\end{array}$ & $2.54 \%$ & $\begin{array}{r}3.34 \% \\
(+6\end{array}$ & $(+6.02)^{* * *}$ & $2.76 \%$ \\
\hline $\begin{array}{l}\text { Second period } \\
(1988-2005)\end{array}$ & $\begin{array}{r}3.16 \% \\
(+7\end{array}$ & $\begin{array}{l}0.11 \% \\
* * *\end{array}$ & $\begin{array}{l}6.76 \% \\
(+5 .\end{array}$ & $2.85 \%$ & $\begin{array}{r}2.12 \% \\
(-1\end{array}$ & $2.62 \%$ & $\begin{array}{r}2.41 \% \\
(+3\end{array}$ & $\begin{array}{l}1.06 \% \\
* * *\end{array}$ & $1.94 \%$ \\
\hline
\end{tabular}

T-statistics of ANOVA test reported between brackets. A positive (negative) sign of the t-statistic indicates that the average of the first sectoral subgroup is greater (lower) than the average of the second subgroup. ${ }^{* * *}$ Significance at $1 \%$ level. For a list of the industries considered in each sectoral group, see Appendix 1. 
Table 2: Structural change in the long run - Dynamic panel model estimation of labour productivity growth trends (Arellano and Bond GMM) ${ }^{*}$

\begin{tabular}{|cccccccccc|}
\hline Period 1970-1987 & AKP-M & AKP-S & MPG-SB & MPG-SI & SIS-N & SIS-P & PGS-M & PGS-S & Total \\
& & & & & & & & & \\
Time trend & 0.476 & -0.392 & 0.908 & -0.281 & -0.441 & -0.163 & 0.244 & -0.108 & 0.312 \\
& $(6.36)^{* * *}$ & $(8.91)^{* * *}$ & $(9.40)^{* * *}$ & $(8.19)^{* * *}$ & $(12.1)^{* * *}$ & $(4.52)^{* * *}$ & $(5.90)^{* * *}$ & $(2.33)^{* *}$ & $(4.55)^{* * *}$ \\
$\Delta \mathbf{L P}$ & 0.759 & 0.855 & 0.483 & 0.967 & 0.854 & 0.902 & 0.812 & 0.903 & 0.795 \\
& $(24.6)^{* * *}$ & $(46.1)^{* * *}$ & $(21.4)^{* * *}$ & $(108.5)^{* * *}$ & $(78.3)^{* * *}$ & $(95.0)^{* * *}$ & $(38.1)^{* * *}$ & $(26.8)^{* * *}$ & $(20.7)^{* * *}$ \\
Wald $\chi^{2}$ & 603.55 & 2122.5 & 456.79 & 11772.9 & 6137.1 & 9032.1 & 1448.0 & 720.25 & 430.09 \\
Sectors & 46 & 69 & 143 & 148 & 139 & 102 & 234 & 51 & 17 \\
Observations & 708 & 1045 & 2184 & 2319 & 2136 & 1600 & 3598 & 807 & 269 \\
\hline
\end{tabular}

\begin{tabular}{|cccccccccc|}
\hline Period 1988-2005 & AKP-M & AKP-S & MPG-SB & MPG-SI & SIS-N & SIS-P & PGS-M & PGS-S & Total \\
& & & & & & & & & \\
Time trend & 0.864 & 0.111 & 2.340 & 0.998 & 0.548 & 0.708 & 0.843 & 0.323 & 0.202 \\
& $(6.53)^{* * *}$ & $(1.94)^{* *}$ & $(14.2)^{* * *}$ & $(11.2)^{* * *}$ & $(12.3)^{* * *}$ & $(10.6)^{* * *}$ & $(16.7)^{* * *}$ & $(7.90)^{* * *}$ & $(4.86)^{* * *}$ \\
$\Delta \mathbf{L P}$ & 0.806 & 0.700 & 0.864 & 0.733 & 0.898 & 0.844 & 0.703 & 0.780 & 0.897 \\
& $(29.1)^{* * *}$ & $(29.9)^{* * *}$ & $(56.9)^{* * *}$ & $(32.6)^{* * *}$ & $(82.9)^{* * *}$ & $(63.2)^{* * *}$ & $(38.9)^{* * *}$ & $(36.7)^{* * *}$ & $(46.0)^{* * *}$ \\
Wald $\chi^{2}$ & 845.47 & 895.67 & 3241.4 & 1065.5 & 6873.2 & 3991.8 & 1515.5 & 1346.7 & 2118.6 \\
Sectors & 68 & 85 & 220 & 169 & 151 & 102 & 280 & 51 & 17 \\
Observations & 1046 & 1402 & 3292 & 2883 & 2646 & 1836 & 4701 & 918 & 306 \\
\hline
\end{tabular}

* Arellano and Bond one-step GMM estimator. T-statistics between brackets. *** Significance at $1 \%$ level; ** Significance at $5 \%$ level. For a list of the industries considered in each sectoral group, see Appendix 1. 
Table 3: The effects of human capital and ICT on sectoral productivity growth - Dynamic panel model estimation (Arellano and Bond GMM) Period 1991-2005

\begin{tabular}{|c|c|c|c|c|c|c|c|c|c|}
\hline & \multirow[t]{2}{*}{$\begin{array}{l}\text { Base } \\
\text { model }\end{array}$} & \multicolumn{7}{|c|}{$\begin{array}{l}\text { Models with slope dummies } \\
\text { (SD) for each sectoral group }\end{array}$} & \multirow[b]{2}{*}{ PGS-S } \\
\hline & & AKP-M & AKP-S & MPG-SB & MPG-SI & SIS-N & SIS-P & PGS-M & \\
\hline$\Delta \mathrm{ICT}$ & $\begin{array}{c}0.024 \\
(50.0)^{* * *}\end{array}$ & $\begin{array}{c}0.025 \\
(53.3)^{* * *}\end{array}$ & - & $\begin{array}{c}0.092 \\
(85.2)^{* * *}\end{array}$ & $\begin{array}{c}0.021 \\
(40.6)^{* * *}\end{array}$ & $\begin{array}{c}-0.155 \\
(269.4)^{* * *}\end{array}$ & $\begin{array}{c}0.009 \\
(18.6)^{* * *}\end{array}$ & $\begin{array}{c}0.022 \\
(49.3)^{* * *}\end{array}$ & $\begin{array}{c}0.018 \\
(36.5)^{* * * *}\end{array}$ \\
\hline$\Delta \mathrm{ICT}$ SD & & $\begin{array}{c}-0.089 \\
(2.44)^{* *}\end{array}$ & - & $\begin{array}{c}-0.259 \\
(216.6)^{* * *}\end{array}$ & $\begin{array}{c}1.127 \\
(21.3)^{* * *}\end{array}$ & $\begin{array}{c}0.345 \\
(299.6)^{* * *}\end{array}$ & $\begin{array}{c}0.611 \\
(20.5)^{* * *}\end{array}$ & $\begin{array}{c}0.687 \\
(21.4)^{* * *}\end{array}$ & $\begin{array}{c}0.276 \\
(4.31)^{* * *}\end{array}$ \\
\hline$\Delta \mathbf{H K}$ & $\begin{array}{c}0.287 \\
(35.2)^{* * *}\end{array}$ & $\begin{array}{c}0.281 \\
(34.2)^{* * *}\end{array}$ & $\begin{array}{c}0.473 \\
(6.16)^{* * *}\end{array}$ & $\begin{array}{c}-0.275 \\
(22.3)^{* * *}\end{array}$ & $\begin{array}{c}0.268 \\
(33.5)^{* * *}\end{array}$ & $\begin{array}{c}3.008 \\
(262.6)^{* * *}\end{array}$ & $\begin{array}{c}0.345 \\
(39.7)^{* * *}\end{array}$ & $\begin{array}{c}0.304 \\
(36.9)^{* * *}\end{array}$ & $\begin{array}{c}0.317 \\
(37.6)^{* * *}\end{array}$ \\
\hline$\Delta$ HK SD & & $\begin{array}{c}0.438 \\
(2.97)^{* * *}\end{array}$ & $\begin{array}{c}-0.658 \\
(2.05)^{* *}\end{array}$ & $\begin{array}{c}3.020 \\
(206.4)^{* * *}\end{array}$ & $\begin{array}{c}1.162 \\
(7.99)^{* * *}\end{array}$ & $\begin{array}{c}-3.458 \\
(235.7)^{* * *}\end{array}$ & $\begin{array}{c}-0.783 \\
(5.07)^{* * *}\end{array}$ & $\begin{array}{c}1.339 \\
(9.94)^{* * *}\end{array}$ & $\begin{array}{c}-1.156 \\
(6.02)^{* * *}\end{array}$ \\
\hline$\Delta \mathbf{L P}$ & $\begin{array}{c}0.586 \\
(993.1)^{* * *}\end{array}$ & $\begin{array}{c}0.586 \\
(979.3)^{* * *}\end{array}$ & $\begin{array}{c}0.853 \\
(153.6)^{* * *}\end{array}$ & $\begin{array}{c}0.563 \\
(922.8)^{* * *}\end{array}$ & $\begin{array}{c}0.572 \\
(1009.2)^{* * *}\end{array}$ & $\begin{array}{c}0.547 \\
(820.5)^{* * *}\end{array}$ & $\begin{array}{c}0.583 \\
(967.9)^{* * *}\end{array}$ & $\begin{array}{c}0.580 \\
(980.2)^{* * *}\end{array}$ & $\begin{array}{c}0.585 \\
(994.3)^{* * *}\end{array}$ \\
\hline Wald $\chi^{2}$ & 1575.86 & $1.60 \mathrm{e}+06$ & $2.44 \mathrm{e}+06$ & $2.31 \mathrm{e}+06$ & $1.52 \mathrm{e}+06$ & $2.08 \mathrm{e}+06$ & $1.58 \mathrm{e}+06$ & $1.44 \mathrm{e}+06$ & $1.49 \mathrm{e}+06$ \\
\hline Sectors & 368 & 368 & 368 & 368 & 368 & 368 & 368 & 368 & 368 \\
\hline Observations & 4565 & 4565 & 4565 & 4565 & 4565 & 4565 & 4565 & 4565 & 4565 \\
\hline
\end{tabular}

* All the regressions include a constant (time trend). Arellano and Bond two-step GMM estimator. T-statistics between brackets: ***significance at $1 \%$ level; **significance at $5 \%$ level. For a list of the industries considered in each sectoral group, see Appendix 1. 
Table 4: Innovation and sectoral productivity growth - Cross-sectional analysis, period 2002-2005 - Base model

\begin{tabular}{|c|c|c|c|c|}
\hline & (1) & (2) & (3) & (4) \\
\hline $\begin{array}{l}\text { Turnover from } \\
\text { novel products }\end{array}$ & $\begin{array}{l}0.00076 \\
(2.07)^{* *}\end{array}$ & $\begin{array}{c}0.00054 \\
(1.56)\end{array}$ & $\begin{array}{c}0.00063 \\
(1.60)\end{array}$ & $\begin{array}{l}0.00101 \\
(2.53)^{* *}\end{array}$ \\
\hline $\begin{array}{c}\text { Process } \\
\text { innovations }\end{array}$ & $\begin{array}{l}0.00171 \\
(2.44)^{* *}\end{array}$ & $\begin{array}{l}0.00159 \\
(2.33)^{* *}\end{array}$ & $\begin{array}{l}0.00154 \\
(2.11)^{* *}\end{array}$ & $\begin{array}{c}0.00113 \\
(1.52)\end{array}$ \\
\hline $\begin{array}{l}\text { Organizational } \\
\text { innovations }\end{array}$ & $\begin{array}{l}0.00061 \\
(2.14)^{* *}\end{array}$ & $\begin{array}{l}0.00069 \\
(2.47)^{* *}\end{array}$ & $\begin{array}{l}0.00063 \\
(2.23)^{* *}\end{array}$ & $\begin{array}{l}0.00073 \\
(2.46)^{* *}\end{array}$ \\
\hline $\begin{array}{c}\text { Export } \\
\text { orientation }\end{array}$ & & $\begin{array}{l}0.00047 \\
(2.55)^{* *}\end{array}$ & $\begin{array}{l}0.00044 \\
(2.24)^{* *}\end{array}$ & $\begin{array}{c}0.00058 \\
(2.80)^{* * *}\end{array}$ \\
\hline $\begin{array}{c}\text { R\&D } \\
\text { orientation }\end{array}$ & & & $\begin{array}{c}0.00072 \\
(1.36)\end{array}$ & $\begin{array}{l}0.00103 \\
(1.91)^{*}\end{array}$ \\
\hline $\begin{array}{c}\text { Acquisition of } \\
\text { machinery \& software }\end{array}$ & & & $\begin{array}{c}0.00083 \\
(1.60)\end{array}$ & $\begin{array}{l}0.00095 \\
(1.85)^{*}\end{array}$ \\
\hline $\begin{array}{c}\text { Training } \\
\text { expenditures }\end{array}$ & & & $\begin{array}{c}0.00077 \\
(2.93)^{* * *}\end{array}$ & $\begin{array}{c}0.00078 \\
(2.89)^{* * *}\end{array}$ \\
\hline $\begin{array}{l}\text { External sources: } \\
\text { Suppliers }\end{array}$ & & & & $\begin{array}{l}0.00082 \\
(2.01)^{* *}\end{array}$ \\
\hline $\begin{array}{c}\text { External sources: } \\
\text { Users }\end{array}$ & & & & $\begin{array}{l}-0.00144 \\
(3.70)^{* * *}\end{array}$ \\
\hline $\begin{array}{l}\text { External sources: } \\
\text { Competitors }\end{array}$ & & & & $\begin{array}{l}0.00148 \\
(2.57)^{* *}\end{array}$ \\
\hline $\begin{array}{l}\text { External sources: } \\
\text { Universities }\end{array}$ & & & & $\begin{array}{l}-0.00166 \\
(1.99)^{* *}\end{array}$ \\
\hline $\begin{array}{l}\text { Country } \\
\text { dummies }\end{array}$ & Yes & Yes & Yes & Yes \\
\hline Adjusted $\mathbf{R}^{2}$ & 0.138 & 0.177 & 0.182 & 0.237 \\
\hline Observations & 319 & 308 & 280 & 249 \\
\hline
\end{tabular}

* All the regressions include a constant. OLS estimation method. T-statistics between brackets:

$* * *$ significance at $1 \%$ level; **significance at $5 \%$ level; *significance at $10 \%$ level. 
Table 5: Innovative characteristics of manufacturing and service industries, and ANOVA tests for differences within each macro-sector

\begin{tabular}{|c|c|c|c|c|c|c|c|c|}
\hline & AKP-M & AKP-S & MPG-SB & MPG-SI & SIS-N & SIS-P & PGS-M & PGS-S \\
\hline Turnover from novel products & \multicolumn{2}{|c|}{$(-1.25)$} & \multicolumn{2}{|c|}{$(+2.44)^{* * *}$} & \multicolumn{2}{|c|}{$(+0.08)$} & \multicolumn{2}{|c|}{$(-0.54)$} \\
\hline Process innovations & \multicolumn{2}{|c|}{$(+0.57)$} & \multicolumn{2}{|c|}{$(-2.02)^{* *}$} & 14.2 & $(+1.55)^{*}$ & \multicolumn{2}{|c|}{$(+0.77)$} \\
\hline Organizational innovations & \multicolumn{2}{|c|}{$(+2.55)^{* * *}$} & \multicolumn{2}{|c|}{$(+2.24)^{* *}$} & 36.7 & 32.9 & \multicolumn{2}{|c|}{$(-2.54)^{* * *}$} \\
\hline Export orientation & \multicolumn{2}{|c|}{$(+6.93)^{* * *}$} & \multicolumn{2}{|c|}{$(+0.61)$} & \multicolumn{2}{|c|}{$(-7.93) * * *$} & \multicolumn{2}{|c|}{$(+8.33)^{* * *}$} \\
\hline$R \& D$ orientation & 97.3 & 106.0 & \multicolumn{2}{|c|}{$(+4.04)^{* * *}$} & \multicolumn{2}{|c|}{$77.0{\stackrel{(+3.09)^{* * *}}{77.7}}^{(+1}$} & 66.7 & ${ }_{* *}^{53.6}$ \\
\hline Acquisition of machinery \& software & 74.9 & 74.4 & \multicolumn{2}{|c|}{$(-1.29)^{*}$} & 77.0 & 77.7 & $(+0.76)$ & 75.5 \\
\hline Training expenditures & \multicolumn{2}{|c|}{$(-2.09)^{* *}$} & \multicolumn{2}{|c|}{$(+3.18)^{* * *}$} & \multicolumn{2}{|c|}{$(+1.88)^{* *}$} & \multicolumn{2}{|c|}{$(-1.77) * *$} \\
\hline External sources: Suppliers & \multicolumn{2}{|c|}{$(+0.69)$} & \multicolumn{2}{|c|}{$(-0.68)$} & \multicolumn{2}{|c|}{$(-0.12)$} & \multicolumn{2}{|c|}{$(-1.54)^{*}$} \\
\hline External sources: Users & \multicolumn{2}{|c|}{29.9} & \multicolumn{2}{|c|}{$(+2.26)^{* *}$} & 27.4 & 24.8 & \multicolumn{2}{|c|}{$(+2.48)^{* * *}$} \\
\hline External sources: Competitors & \multicolumn{2}{|c|}{14.1} & \multicolumn{2}{|c|}{$(+0.38)$} & \multicolumn{2}{|c|}{$(+2.18)^{* *}$} & 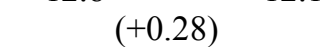 & 12.1 \\
\hline External sources: Universities & \multicolumn{2}{|c|}{$(-2.15)^{* *}$} & 8.0 & 8.2 & 4.4 & 3.7 & 4.1 & 2.8 \\
\hline
\end{tabular}

T-statistics of ANOVA test reported between brackets. A positive (negative) sign of the t-statistic indicates that the average of the first sectoral subgroup is greater (lower) than the average of the second subgroup. ${ }^{* *}$ Significance at $1 \%$ level; ${ }^{* *}$ significance at $5 \%$ level; * significance at $10 \%$ level. For a list of the industries considered in each sectoral group, see Appendix 1. 
Table 6: Innovation and sectoral productivity growth: cross-sectional analysis, period 2002-2005 - Model with slope dummies (SD) for each sectoral group

\begin{tabular}{|c|c|c|c|c|c|c|}
\hline & AKP-S & MPG-SB & MPG-SI & SIS-N & PGS-M & All SDs \\
\hline $\begin{array}{l}\text { Turnover from } \\
\text { novel products }\end{array}$ & $\begin{array}{c}0.00129 \\
(3.24)^{* * *}\end{array}$ & $\begin{array}{c}0.00055 \\
(1.26)\end{array}$ & $\begin{array}{l}0.00107 \\
(2.70)^{* *}\end{array}$ & $\begin{array}{c}0.00122 \\
(3.09)^{* * *}\end{array}$ & $\begin{array}{l}0.00100 \\
(2.52)^{* *}\end{array}$ & $\begin{array}{c}0.00128 \\
(2.93)^{* * *}\end{array}$ \\
\hline $\begin{array}{c}\text { Process } \\
\text { innovations }\end{array}$ & $\begin{array}{l}0.00160 \\
(2.17)^{* *}\end{array}$ & $\begin{array}{c}0.00097 \\
(1.31)\end{array}$ & $\begin{array}{c}0.00111 \\
(1.49)\end{array}$ & $\begin{array}{l}0.00129 \\
(1.78)^{*}\end{array}$ & $\begin{array}{c}0.00112 \\
(1.52)\end{array}$ & $\begin{array}{l}0.00165 \\
(2.31)^{* *}\end{array}$ \\
\hline $\begin{array}{c}\text { Organizational } \\
\text { innovations }\end{array}$ & $\begin{array}{l}0.00063 \\
(2.14)^{* *}\end{array}$ & $\begin{array}{l}0.00066 \\
(2.22)^{* *}\end{array}$ & $\begin{array}{c}0.00867 \\
(2.91)^{* * *}\end{array}$ & $\begin{array}{l}0.00057 \\
(1.92)^{*}\end{array}$ & $\begin{array}{l}0.00069 \\
(2.32)^{* *}\end{array}$ & $\begin{array}{c}0.00048 \\
(1.60)\end{array}$ \\
\hline $\begin{array}{c}\text { Export } \\
\text { orientation }\end{array}$ & $\begin{array}{l}0.00047 \\
(2.27)^{* *}\end{array}$ & $\begin{array}{l}0.00051 \\
(2.47)^{* *}\end{array}$ & $\begin{array}{c}0.00069 \\
(3.11)^{* * *}\end{array}$ & $\begin{array}{c}0.00081 \\
(3.37)^{* * *}\end{array}$ & $\begin{array}{c}0.00061 \\
(2.95)^{* * *}\end{array}$ & $\begin{array}{c}0.00090 \\
(3.31)^{* * *}\end{array}$ \\
\hline $\begin{array}{c}R \& D \\
\text { orientation }\end{array}$ & $\begin{array}{l}0.00116 \\
(2.21)^{* *}\end{array}$ & $\begin{array}{l}0.00094 \\
(1.77)^{*}\end{array}$ & $\begin{array}{l}0.00092 \\
(1.74)^{*}\end{array}$ & $\begin{array}{c}0.00077 \\
(1.44)\end{array}$ & $\begin{array}{l}0.00099 \\
(1.85)^{*}\end{array}$ & $\begin{array}{c}0.00064 \\
(1.24)\end{array}$ \\
\hline $\begin{array}{c}\text { Acquisition of } \\
\text { machinery \& software }\end{array}$ & $\begin{array}{l}0.00103 \\
(2.05)^{* *}\end{array}$ & $\begin{array}{l}0.00092 \\
(1.81)^{*}\end{array}$ & $\begin{array}{c}0.00083 \\
(1.63)\end{array}$ & $\begin{array}{c}0.00078 \\
(1.54)\end{array}$ & $\begin{array}{l}0.00099 \\
(1.95)^{*}\end{array}$ & $\begin{array}{c}0.00074 \\
(1.54)\end{array}$ \\
\hline $\begin{array}{c}\text { Training } \\
\text { expenditures }\end{array}$ & $\begin{array}{c}0.00099 \\
(3.66)^{* * *}\end{array}$ & $\begin{array}{l}0.00068 \\
(2.48)^{* *}\end{array}$ & $\begin{array}{l}0.00088 \\
(3.29)^{* * *}\end{array}$ & $\begin{array}{l}0.00056 \\
(2.10)^{* *}\end{array}$ & $\begin{array}{c}0.00073 \\
(2.67)^{* * *}\end{array}$ & $\begin{array}{l}0.00069 \\
(2.57)^{* *}\end{array}$ \\
\hline $\begin{array}{l}\text { External sources: } \\
\text { Suppliers }\end{array}$ & $\begin{array}{c}0.00061 \\
(1.51)\end{array}$ & $\begin{array}{l}0.00075 \\
(1.83)^{*}\end{array}$ & $\begin{array}{l}0.00103 \\
(2.53)^{* *}\end{array}$ & $\begin{array}{l}0.00105 \\
(2.56)^{* *}\end{array}$ & $\begin{array}{l}0.00093 \\
(2.24)^{* *}\end{array}$ & $\begin{array}{c}0.00113 \\
(2.81)^{* * *}\end{array}$ \\
\hline $\begin{array}{c}\text { External sources: } \\
\text { Users }\end{array}$ & $\begin{array}{l}-0.00155 \\
(4.02)^{* * *}\end{array}$ & $\begin{array}{l}-0.00148 \\
(3.79)^{* * *}\end{array}$ & $\begin{array}{l}-0.00156 \\
(3.98)^{* * *}\end{array}$ & $\begin{array}{l}-0.00112 \\
(2.81)^{* * *}\end{array}$ & $\begin{array}{l}-0.00145 \\
(3.75)^{* * *}\end{array}$ & $\begin{array}{l}-0.00150 \\
(3.70)^{* * *}\end{array}$ \\
\hline $\begin{array}{l}\text { External sources: } \\
\text { Competitors }\end{array}$ & $\begin{array}{l}0.00136 \\
(2.42)^{* *}\end{array}$ & $\begin{array}{l}0.00138 \\
(2.42)^{* *}\end{array}$ & $\begin{array}{c}0.00173 \\
(3.01)^{* * *}\end{array}$ & $\begin{array}{c}0.00083 \\
(1.33)\end{array}$ & $\begin{array}{l}0.00145 \\
(2.53)^{* *}\end{array}$ & $\begin{array}{l}0.00103 \\
(1.70)^{*}\end{array}$ \\
\hline $\begin{array}{l}\text { External sources: } \\
\text { Universities }\end{array}$ & $\begin{array}{c}-0.00075 \\
(0.86)\end{array}$ & $\begin{array}{c}-0.00148 \\
(1.77)^{*}\end{array}$ & $\begin{array}{c}-0.00155 \\
(1.88)^{*}\end{array}$ & $\begin{array}{c}-0.00135 \\
(1.64)\end{array}$ & $\begin{array}{l}-0.00170 \\
(2.04)^{* *}\end{array}$ & $\begin{array}{c}-0.00037 \\
(0.45)\end{array}$ \\
\hline $\begin{array}{l}\text { SD for AKP-S: } \\
\text { Turnover from } \\
\text { novel products }\end{array}$ & $\begin{array}{l}-0.00448 \\
(3.25)^{* * *}\end{array}$ & & & & & $\begin{array}{l}-0.00397 \\
(3.02)^{* * *}\end{array}$ \\
\hline $\begin{array}{l}\text { SD for MPG-SB: } \\
\text { Turnover from } \\
\text { novel products }\end{array}$ & & $\begin{array}{l}0.00136 \\
(2.38)^{* *}\end{array}$ & & & & $\begin{array}{c}0.00077 \\
(1.36)\end{array}$ \\
\hline $\begin{array}{l}\text { SD for MPG-SI: } \\
\text { Organizational } \\
\text { innovations }\end{array}$ & & & $\begin{array}{l}-0.00159 \\
(2.28)^{* *}\end{array}$ & & & $\begin{array}{l}-0.00130 \\
(1.99)^{* *}\end{array}$ \\
\hline $\begin{array}{c}\text { SD for MPG-SI: } \\
\text { Export } \\
\text { orientation }\end{array}$ & & & $\begin{array}{l}-0.00117 \\
(2.16)^{* *}\end{array}$ & & & $\begin{array}{l}-0.00135 \\
(2.56)^{* *}\end{array}$ \\
\hline $\begin{array}{c}\text { SD for SIS-N: } \\
\text { Export } \\
\text { orientation }\end{array}$ & & & & $\begin{array}{l}-0.00273 \\
(2.62)^{* * *}\end{array}$ & & $\begin{array}{l}-0.00297 \\
(3.01)^{* * *}\end{array}$ \\
\hline
\end{tabular}


SD for MPG-SI:

R\&D

orientation

0.00183

0.00186

$(3.20)^{* * *}$

SD for SIS-N:

R\&D

orientation

0.00203

$(2.93)^{* * *}$

0.00196

$(3.79) * * *$

Acquisition of

machinery \& software

SD for SIS-N:

Acquisition of

machinery \& software

SD for PGS-M:

Training

expenditures

SD for MPG-SI:

External sources:

Suppliers

SD for AKP-S:

External sources:

Users

0.00104

(1.31)

SD for SIS-N:

External sources:

Users

SD for SIS-N:

External sources:

Competitors

$\begin{array}{ccccccc}\begin{array}{c}\text { Country } \\ \text { dummies }\end{array} & \text { Yes } & \text { Yes } & \text { Yes } & \text { Yes } & \text { Yes } & \text { Yes } \\ \text { Adjusted } \mathbf{R}^{2} & 0.278 & 0.253 & 0.278 & 0.287 & 0.246 & 0.375 \\ \text { Observations } & 249 & 249 & 249 & 249 & 249 & 249\end{array}$

For a list of the industries considered in each sectoral group, see Appendix 1.
0.00125

$(2.90) * * *$
$-0.00103$

$(2.85)^{* * *}$

00242

$(3.18)^{* * *}$

0.00114

(1.50)

$-0.00394$

$-0.00363$

$(3.43)^{* * *}$

$(3.35)^{* * *}$

0.00329

0.00301

$(2.44)^{* *}$

$(2.35)^{* *}$ 
Table 7: The determinants of cross-country differences - Dynamic panel model estimation (Arellano and Bond GMM)

\begin{tabular}{|c|c|c|c|c|c|c|}
\hline & \multicolumn{3}{|c|}{$\begin{array}{l}\text { Longer period: } \\
\text { 1980-2005 }\end{array}$} & \multicolumn{3}{|c|}{$\begin{array}{l}\text { Shorter period: } \\
1990-2005\end{array}$} \\
\hline & (1) & (2) & (3) & (4) & (5) & (6) \\
\hline$\Delta$ GDP per capita & $\begin{array}{l}0.3145 \\
(4.19)^{* * *}\end{array}$ & $\begin{array}{l}0.4374 \\
(3.88)^{* * *}\end{array}$ & $\begin{array}{l}0.4187 \\
(4.33)^{* * *}\end{array}$ & $\begin{array}{l}0.4248 \\
(3.56)^{* * *}\end{array}$ & $\begin{array}{c}0.3557 \\
(2.11)^{* *}\end{array}$ & $\begin{array}{l}0.2468 \\
(1.76)^{*}\end{array}$ \\
\hline$\Delta$ Physical capital & $\begin{array}{l}0.2579 \\
(6.96)^{* * *}\end{array}$ & $\begin{array}{l}0.2486 \\
(6.21)^{* * *}\end{array}$ & $\begin{array}{l}0.2161 \\
(5.35)^{* * *}\end{array}$ & $\begin{array}{l}0.2633 \\
(4.18)^{* * * *}\end{array}$ & $\begin{array}{l}0.2305 \\
(3.33)^{* * *}\end{array}$ & $\begin{array}{l}0.2052 \\
(3.43)^{* * *}\end{array}$ \\
\hline$\Delta$ Human capital & $\begin{array}{l}0.0473 \\
(2.08)^{* *}\end{array}$ & $\begin{array}{l}0.0330 \\
(1.35)\end{array}$ & $\begin{array}{l}0.0286 \\
(1.21)\end{array}$ & $\begin{array}{l}0.0357 \\
(0.74)\end{array}$ & $\begin{array}{l}0.0495 \\
(1.05)\end{array}$ & $\begin{array}{l}0.0589 \\
(1.34)\end{array}$ \\
\hline$\Delta \mathrm{ICT}$ Exports & $\begin{array}{l}0.0016 \\
(3.43)^{* * *}\end{array}$ & $\begin{array}{l}0.0012 \\
(2.36)^{* *}\end{array}$ & $\begin{array}{l}0.0013 \\
(2.71)^{* * *}\end{array}$ & $\begin{array}{l}0.0018 \\
(2.75)^{* * *}\end{array}$ & $\begin{array}{l}0.0016 \\
(2.22)^{* *}\end{array}$ & $\begin{array}{l}0.0015 \\
(2.42)^{* *}\end{array}$ \\
\hline$\Delta$ Patents & $\begin{array}{l}0.1190 \\
(5.84)^{* * *}\end{array}$ & $\begin{array}{l}0.0952 \\
(3.04)^{* * *}\end{array}$ & $\begin{array}{l}0.1131 \\
(4.26)^{* * *}\end{array}$ & $\begin{array}{l}0.1780 \\
(4.35)^{* * *}\end{array}$ & $\begin{array}{c}0.1414 \\
(2.33)^{* *}\end{array}$ & $\begin{array}{l}0.2174 \\
(5.32)^{* * *}\end{array}$ \\
\hline$\Delta$ Mobile telephony & & & & $\begin{array}{l}0.0106 \\
(1.61)\end{array}$ & $\begin{array}{l}0.0052 \\
(0.78)\end{array}$ & $\begin{array}{l}0.0042 \\
(0.65)\end{array}$ \\
\hline$\Delta$ Empl AKP-M & & $\begin{array}{l}0.0554 \\
(0.71)\end{array}$ & & & $\begin{array}{l}0.1163 \\
(0.84)\end{array}$ & \\
\hline$\Delta$ Empl AKP-S & & $\begin{array}{l}-0.0651 \\
(2.45)^{* *}\end{array}$ & $\begin{array}{l}-0.0565 \\
(2.38)^{* *}\end{array}$ & & $\begin{array}{l}-0.1304 \\
(2.69)^{* * *}\end{array}$ & $\begin{array}{l}-0.1752 \\
(4.46)^{* * *}\end{array}$ \\
\hline$\Delta$ Empl MPG-SB & & $\begin{array}{l}0.0896 \\
(1.37)\end{array}$ & $\begin{array}{l}0.0481 \\
(0.97)\end{array}$ & & $\begin{array}{l}0.1069 \\
(0.94)\end{array}$ & $\begin{array}{l}0.1540 \\
(2.31)^{* *}\end{array}$ \\
\hline$\Delta$ Empl MPG-SI & & $\begin{array}{l}-0.0465 \\
(0.69)\end{array}$ & & & $\begin{array}{l}0.0328 \\
(0.25)\end{array}$ & \\
\hline$\Delta$ Empl SIS-N & & $\begin{array}{l}0.1484 \\
(3.92)^{* * *}\end{array}$ & $\begin{array}{l}0.1220 \\
(3.31)^{* * *}\end{array}$ & & $\begin{array}{c}0.2404 \\
(3.84)^{* * *}\end{array}$ & $\begin{array}{l}0.2569 \\
(4.37)^{* * *}\end{array}$ \\
\hline$\Delta$ Empl SIS-P & & $\begin{array}{l}0.0257 \\
(0.65)\end{array}$ & & & $\begin{array}{l}-0.0708 \\
(0.94)\end{array}$ & \\
\hline$\Delta$ Empl PGS-M & & $\begin{array}{l}-0.0590 \\
(1.26)\end{array}$ & & & $\begin{array}{l}-0.1332 \\
(1.68)^{*}\end{array}$ & \\
\hline$\Delta$ Empl PGS-S & & $\begin{array}{l}-0.0342 \\
(1.77)^{*}\end{array}$ & & & $\begin{array}{l}-0.0294 \\
(0.76)\end{array}$ & \\
\hline Wald $\chi^{2}$ & 189.40 & 279.38 & 252.45 & 107.31 & 159.99 & 165.11 \\
\hline Countries & 18 & 18 & 18 & 18 & 18 & 18 \\
\hline Observations & 89 & 83 & 83 & 51 & 50 & 50 \\
\hline
\end{tabular}

* All the regressions include a constant, plus a time dummy for each 5-year subperiod. Arellano and Bond one-step GMM estimator. T-statistics between brackets: ***significance at $1 \%$ level;

$* *$ significance at $5 \%$ level; * significance at $10 \%$ level. 